\title{
Distinct Inhibitory Neurons Exert Temporally Specific Control over Activity of a Motoneuron Receiving Concurrent Excitation and Inhibition
}

\author{
Kosei Sasaki, Vladimir Brezina, Klaudiusz R. Weiss, and Jian Jing \\ Department of Neuroscience, Mount Sinai School of Medicine, New York, New York 10029
}

\begin{abstract}
Recent work suggests that concurrent excitation and inhibition originating in central pattern generators (CPGs) may be used to control rhythmic motoneuronal activity. The specific roles that the inhibition plays in such cases are not well understood, however, in part because of the lack of identification of presynaptic inhibitory neurons. Here we demonstrate that, in the Aplysia feeding CPG, inhibitory inputs may be critical for flexible control of the activity of motoneurons in different forms of behavior. The feeding CPG generates ingestive and egestive motor programs, differing in the high and low activity, respectively, of the motoneuron B8 during the retraction phase of the programs. We show that, during retraction, B8 receives concurrent excitation and inhibition that produces a highconductance state. The inhibition originates in two types of CPG neurons, B4/5 and B70, that are more active in egestion than ingestion and play a role in suppressing B8 activity during egestion. In turn, the activities of both B4/5 and B70 are suppressed by the ingestionpromoting descending interneuron CBI-3 (for cerebral-buccal interneuron 3). Thus, concurrent excitation and inhibition may be an effective means of controlling motoneuronal activity in a behavior-dependent manner. More detailed analyses reveal, furthermore, that B4/5 and B70 exert complementary actions by acting preferentially in the early and late part of retraction, respectively. Thus, the use of multiple neurons to generate inhibitory inputs to motoneurons that receive concurrent excitation and inhibition brings an additional level of flexibility that allows a temporally specific control of motoneuronal activity within a single phase of motor programs.
\end{abstract}

\section{Introduction}

Rhythm generation often results from an interplay of excitation and inhibition. To produce rhythmic activity of motoneurons, rhythm-generating networks, or central pattern generators (CPGs), may use excitation and inhibition in at least two modes. In the first mode (Brown, 1911), the motoneurons are controlled by alternating excitatory and inhibitory inputs from the CPG neurons, being excited by the CPG neurons that are active in the agonist phase and inhibited by those that are active in the antagonist phase. Consequently, the motoneurons fire in the agonist phase. In the second mode, the motoneurons are controlled by concurrent excitation and inhibition (Berg et al., 2007). The functional consequences of the inhibition differ in the two modes: in the first mode, the inhibition affects primarily the phasing of the motoneuronal activity, whereas in the second mode, it also has a direct impact on the level of the activity. Recently, concurrent excitation and inhibition has generated significant interests because of its prevalence in cortical networks (Destexhe et al., 2003); it has been studied also in spinal (Berg et al., 2007) and invertebrate (Baca et al., 2008) networks. However, the conclusions of these studies are often tentative because the

Received June 26, 2009; revised Aug. 1, 2009; accepted Aug. 5, 2009.

This work was supported by National Institutes of Health Grants MH 035564 and NS 066587.

Correspondence should be addressed to Dr. Jian Jing, Department of Neuroscience, Box 1065, Mount Sinai School

of Medicine, 1 Gustave Levy Place, New York, NY 10029. E-mail: jingj01@gmail.com.

DOI:10.1523/JNEUROSCI.3051-09.2009

Copyright $\odot 2009$ Society for Neuroscience ～0270-6474/09/2911732-13\$15.00/0 presynaptic inhibitory neurons remain unidentified. For example, within a single phase of a rhythm, it is typically unknown how many inhibitory neurons there are and whether they are homogenous or heterogeneous.

Taking advantage of the identifiable neurons in the Aplysia feeding motor network, we examined the functional roles of inhibition of a motoneuron, B8, whose activity within a single motor program is controlled by concurrent excitation and inhibition. The Aplysia feeding network is multifunctional in that it can generate at least two major classes of motor programs: ingestive and egestive. B8 is a key output neuron of the network because, during different motor programs, B8 expresses distinct activity patterns (Morton and Chiel, 1993b) relative to the protraction-retraction sequence that is invariant in all programs. Specifically, in ingestive programs, B8 is predominantly active during retraction, whereas in egestive programs, $\mathrm{B} 8$ is predominantly active during protraction. The $\mathrm{B} 8$ activity is under the exquisite control of the feeding network through direct and indirect inputs. Here, we demonstrate that direct inhibition of B8 during retraction originates in two distinct types of inhibitory CPG neurons, B4/5 (Kabotyanski et al., 1998; Jing and Weiss, 2001) and the newly described B70, which are more active during egestion and therefore decrease the activity of $\mathrm{B} 8$ during retraction in egestive programs. Furthermore, B4/5 and B70 preferentially act during the early and late part of retraction, respectively. Thus, the functions of the B4/5 and B70 inhibitory neurons within retraction are complementary, an organizational feature that may allow temporally specific control of motoneuronal ac- 
tivity for additional flexibility. This conceptualization is different from previous ones that assumed that different inhibitory neurons active within a single phase function additively, as would be the case if they fired together. It also offers an alternative to the earlier hypothesis that flexible motoneuronal activity is generated by excitatory interneurons (Orlovsky et al., 1999).

\section{Materials and Methods}

Experiments were performed on Aplysia californica (100-200 g) obtained from Marinus. Animals were anesthetized by injection of isotonic $\mathrm{MgCl}_{2}$ (30-50\% of body weight). The cerebral and buccal ganglia were removed, desheathed, and pinned in a recording chamber $\left(14-17^{\circ} \mathrm{C}\right.$; volume, $\sim 1.1 \mathrm{ml}$ ) perfused at $0.33 \mathrm{ml} / \mathrm{min}$. The composition of normal artificial seawater was the following (in $\mathrm{mM}$ ): $460 \mathrm{NaCl}, 10 \mathrm{KCl}, 11 \mathrm{CaCl}_{2}, 55$ $\mathrm{MgCl}_{2}$, and $10 \mathrm{HEPES}, \mathrm{pH}$ 7.6. To suppress polysynaptic pathways, a highdivalent cation saline was used (in mM: $368 \mathrm{NaCl}, 10 \mathrm{KCl}, 13.8 \mathrm{CaCl}_{2}, 101$ $\mathrm{MgCl}_{2}$, and $10 \mathrm{HEPES}, \mathrm{pH}$ 7.6). In some experiments, APGWamide (AlaPro-Gly-Trp- $\mathrm{NH}_{2}$ ) (AnaSpec) was applied by bath perfusion.

Electrophysiology. Intracellular recordings were made using singlebarrel electrodes (4-10 M $\Omega$ ) filled with $2 \mathrm{M} \mathrm{K}$-acetate and $30 \mathrm{~mm} \mathrm{KCl}$. Intracellular signals were acquired using an AxoClamp 2B amplifier (MDS Analytical Technologies) or a Getting model 5A amplifier (Getting Instruments). Extracellular signals were acquired from polyethylene suction electrodes using a differential alternating current amplifier (model 1700; A-M Systems). A Grass stimulator model S88 (Grass Instruments) was used for stimulation.

Voltage-clamp experiments. To prevent spiking and to avoid artifacts arising from the voltage dependence of the conductance of $\mathrm{B} 8$, we measured B8 conductance during motor programs under voltage-clamp conditions. B8 was voltage clamped using the single-electrode voltage-clamp mode of the Axoclamp 2B. B8 was held close to its normal resting membrane potential, usually at $-60 \mathrm{mV}$. Conductance changes were measured using small, brief, repetitive voltage pulses (see figure legends of Fig. 2, 3).

Identification of neurons and the type of motor programs. Neurons other than B70 were identified as described previously (Rosen et al., 1991, 2000; Hurwitz and Susswein, 1996; Hurwitz et al., 1997; Jing and Weiss, 2001; Morgan et al., 2002). B70 is reported here for the first time. To reveal B70 morphology, B70 was ionophoretically injected with Alexa 488 dye (Invitrogen). To allow the dye to diffuse, we maintained the preparations for $2-3 \mathrm{~h}$ at $15-17^{\circ} \mathrm{C}$ or $4^{\circ} \mathrm{C}$ overnight. The preparations were viewed and photographed live, with an appropriate filter using a fluorescence microscope (Nikon).

Motor programs were elicited via intracellular stimulation of cerebralbuccal interneuron-2 (CBI-2) at $10 \mathrm{~Hz}$. Each current pulse was set to trigger a single action potential. CBI-2 stimulation was manually terminated after the protraction phase ended as determined on the basis of the activity of the $\mathrm{I} 2$ nerve. In some experiments, motor programs were elicited by costimulation of CBI-2 and CBI-3. This procedure was shown previously to increase the ingestiveness of the CBI-2-elicited motor programs (Morgan et al., 2002). Motor programs were also elicited extracellularly via stimulation of the esophageal nerve (EN) at $2-5 \mathrm{~Hz}, 8-10 \mathrm{~V}$.

The feeding CPG generates several types of motor programs. The major components of these programs are those that generate the protraction-retraction and the opening-closing movements of the radula. Regardless of the type of motor program, the protraction-retraction components occur in a fixed sequence in which the protraction phase precedes the retraction phase. The protraction phase was monitored by the activity of the I2 nerve, which contains axons of protractor motoneurons $\mathrm{B} 31 / 32$ and $\mathrm{B} 61 / 62$ that are active only during the protraction phase and are actively inhibited during the retraction phase (Hurwitz et al., 1996). The retraction phase was monitored by the activity of the buccal nerve 2 (BN2), which contains axons of retractor motoneurons, including B6 and B9 (Morton and Chiel, 1993a,b).

In contrast to the phase-invariant characteristics of the protractionretraction sequence, the timing of the radula opening-closing components depends on the type of program (Morton and Chiel, 1993a,b; Church and Lloyd, 1994; Nargeot et al., 1997; Jing and Weiss, 2001; Morgan et al., 2002). Briefly, when the radula closing motoneuron B8 fires predominantly during retraction, and thus (in the intact animal)

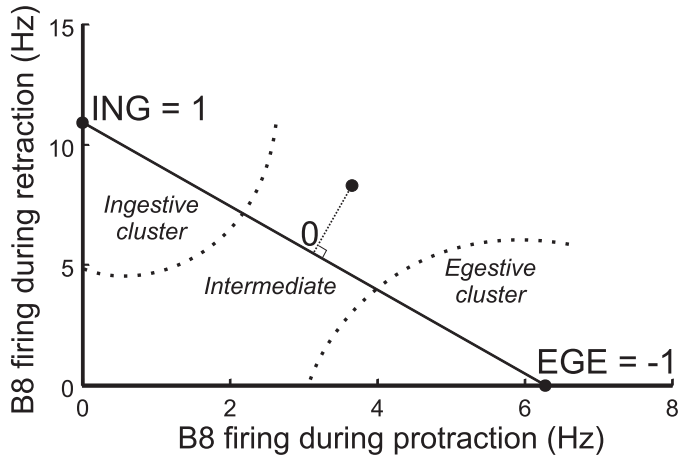

Figure 1. Definition of ingestiveness index. Each motor program cycle can be represented in a two-dimensional plane in which the $x$-axis plots the B8 activity (firing frequency) during protraction and the $y$-axis the $\mathrm{B} 8$ activity during retraction. Because $\mathrm{B} 8$ is predominantly active during protraction in egestive programs and during retraction in ingestive programs, egestive programs occupy a cluster in the bottom right corner of the plane, and ingestive programs occupy a cluster in the top left corner (dotted lines). Motor programs that fall between the two clusters are defined as intermediate programs. To define a one-dimensional index, we first defined an extreme ING, a program with B8 protraction activity of $0 \mathrm{~Hz}$ and $\mathrm{B} 8$ retraction activity of $10.93 \mathrm{~Hz}$, to which we assigned an ingestiveness index of 1 . Similarly, we defined an extreme EGE, a program with B8 protraction activity of $6.28 \mathrm{~Hz}$ and $\mathrm{B} 8$ retraction activity of $0 \mathrm{~Hz}$, with an ingestiveness index of -1 . All other motor programs were then mapped orthogonally (see Materials and Methods) onto the linear axis between ING and EGE to obtain for each an ingestiveness index between -1 and 1 . The data point illustrated maps, for example, to the midpoint between ING and EGE and so has an ingestiveness index of 0 .

helps bring the food into the buccal cavity, the program is considered to be ingestive. When B8 fires predominantly during protraction, and thus helps in removing an inedible object from the buccal cavity, the program is considered to be egestive. Finally, when B8 fires during both protraction and retraction, the programs are defined as intermediate (Fig. 1).

To facilitate analysis of the relationship between the activities of the CPG elements and the degree of ingestiveness or egestiveness of the motor programs, we defined a one-dimensional linear ingestiveness index for the motor programs. Usually, ingestiveness and egestiveness are represented in a two-dimensional plane, with B8 activity (firing frequency) during protraction plotted on the $x$-axis and $\mathrm{B} 8$ activity during retraction plotted on the $y$-axis (Fig. 1) (Jing and Weiss, 2002; Morgan et al., 2002; Proekt et al., 2004, 2007, 2008; Wu et al., 2007). By definition (see above), programs are considered ingestive when B8 is mostly active during retraction and egestive when $\mathrm{B} 8$ is mostly active during protraction. To calculate the ingestiveness index, we first defined extreme ingestive and extreme egestive locations in the two-dimensional plane. For the extreme ingestive location (ING), we selected the minimum B8 activity during protraction $(0 \mathrm{~Hz})$ and the maximum $\mathrm{B} 8$ activity during retraction $(10.93 \mathrm{~Hz})$ that we observed in our entire motor program dataset $(n=$ 468 ) and assigned ING an ingestiveness index of 1 . Similarly, for the extreme egestive location (EGE), we selected the minimum B8 activity during retraction $(0 \mathrm{~Hz})$ and the maximum $\mathrm{B} 8$ activity during protraction $(6.28 \mathrm{~Hz})$ observed in the dataset and assigned EGE an ingestiveness index of -1 . We then treated the line connecting EGE and ING as a one-dimensional linear axis ranging from -1 to 1 . We mapped each motor program represented in the two-dimensional plane orthogonally onto this axis and so obtained its ingestiveness index. Specifically, if the ingestiveness index was defined to be 1 for ING with coordinates $\left(x_{1}, y_{1}\right)$ in the two-dimensional plane and -1 for EGE with coordinates $\left(x_{2}, y_{2}\right)$, then for any other motor program with coordinates $(x, y)$, the ingestiveness index was given by

Index $=\left(-x_{1}^{2}+2 x\left(x_{1}-x_{2}\right)+x_{2}^{2}+2 y y_{1}-y_{1}^{2}-2 y y_{2}+y_{2}^{2}\right)$

$$
/\left(x_{1}^{2}-2 x_{1} x_{2}+x_{2}^{2}+\left(y_{1}-y_{2}\right)^{2}\right) .
$$

Data analysis. Electrophysiological recordings were digitized online with Axoscope and plotted with CorelDraw. Graphs were plotted using SigmaPlot 8 (SPSS) or Axum (Mathsoft). Data are expressed as mean \pm SEM. 
Statistical tests were performed using Prism 4 (GraphPad Software). They included Student's $t$ test, repeated-measures one-way ANOVA, and two-way ANOVA, as appropriate. Data that showed significant effects in ANOVA were further analyzed in individual comparisons with Bonferroni's correction. Correlations between two sets of data were performed to obtain Pearson's correlation coefficient $(r)$. The correlation coefficient ranges from -1 to 1 , with -1 indicating a perfect inverse correlation and 1 indicating a perfect positive correlation. In all statistical tests, effects were considered statistically significant when $p<0.05$.

\section{Results}

In the multifunctional feeding network of Aplysia, the radula closing motoneuron B8 is a critical output neuron that is an indicator of which type of program, ingestive, egestive, or intermediate (Fig. 1), is being expressed. Each motor program produced by the feeding network, whether it is ingestive, egestive, or intermediate, is biphasic insofar as it begins with a protraction phase (Fig. $2 A$, open bar), followed by a retraction phase (Fig. 2A, filled bar). However, B8 activity differs in the different types of programs. In ingestive programs, B8 is predominantly active during retraction and weakly active during protraction (Fig. 2A1), whereas in egestive programs, it is predominantly active during protraction and weakly active during retraction (Fig. 2A2). In intermediate programs, B8 is moderately active during both protraction and retraction. Motor programs were elicited through the activation of two input pathways to the feeding CPG, CBI-2 (Fig. 2A1) or EN (Fig. 2A2) (Chiel et al., 1986; Morton and Chiel, 1993a,b; Church and Lloyd, 1994; Nargeot et al., 1997; Jing and Weiss, 2001, 2005; Morgan et al., 2002; Proekt et al., 2004, 2007; Jing et al., 2007). CBI-2 is a higher-order interneuron receiving inputs from head sensory organs and, when activated, can elicit all three types of programs. EN receives inputs, in part, from the gut and, when activated, can elicit mostly egestive programs.

Inspection of expanded intracellular recordings of B8 activity (Fig. $2 B$ ) suggested that $B 8$ receives both excitation and inhibition throughout the motor program, i.e., during both protraction and retraction. In this report, we focus on how B8 activity is controlled during retraction. Excitatory synaptic inputs could be observed as maintained depolarization from the resting potential. We found that the amplitude of the depolarization during retraction was on average $16.08 \pm 1.01 \mathrm{mV}$ in CBI-2-elicited programs $(n=30)$ and
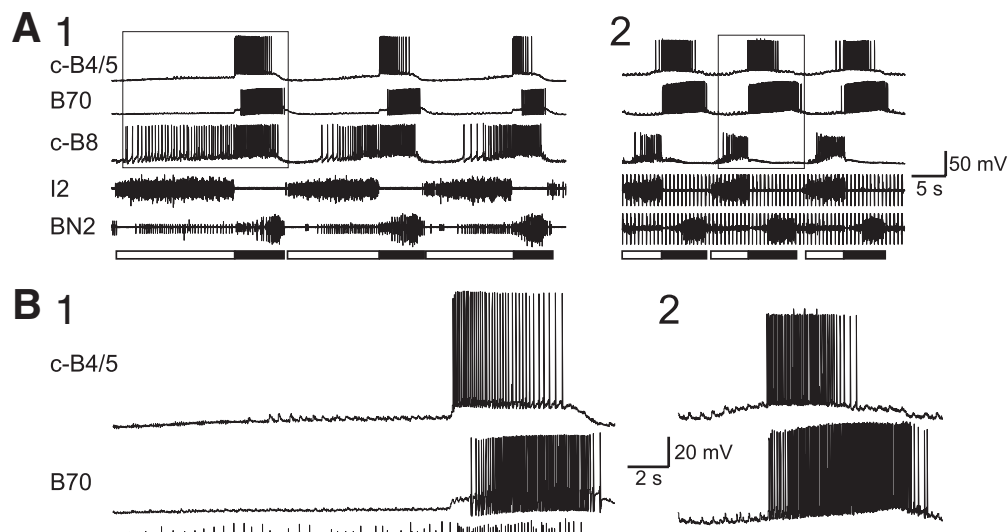

B70
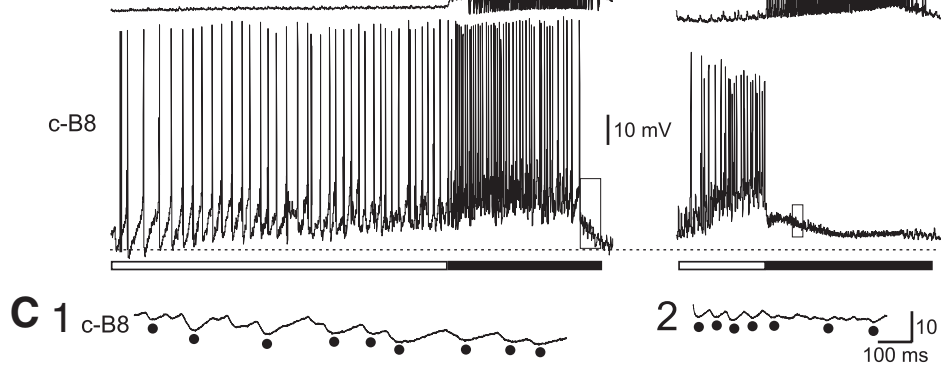

D 1
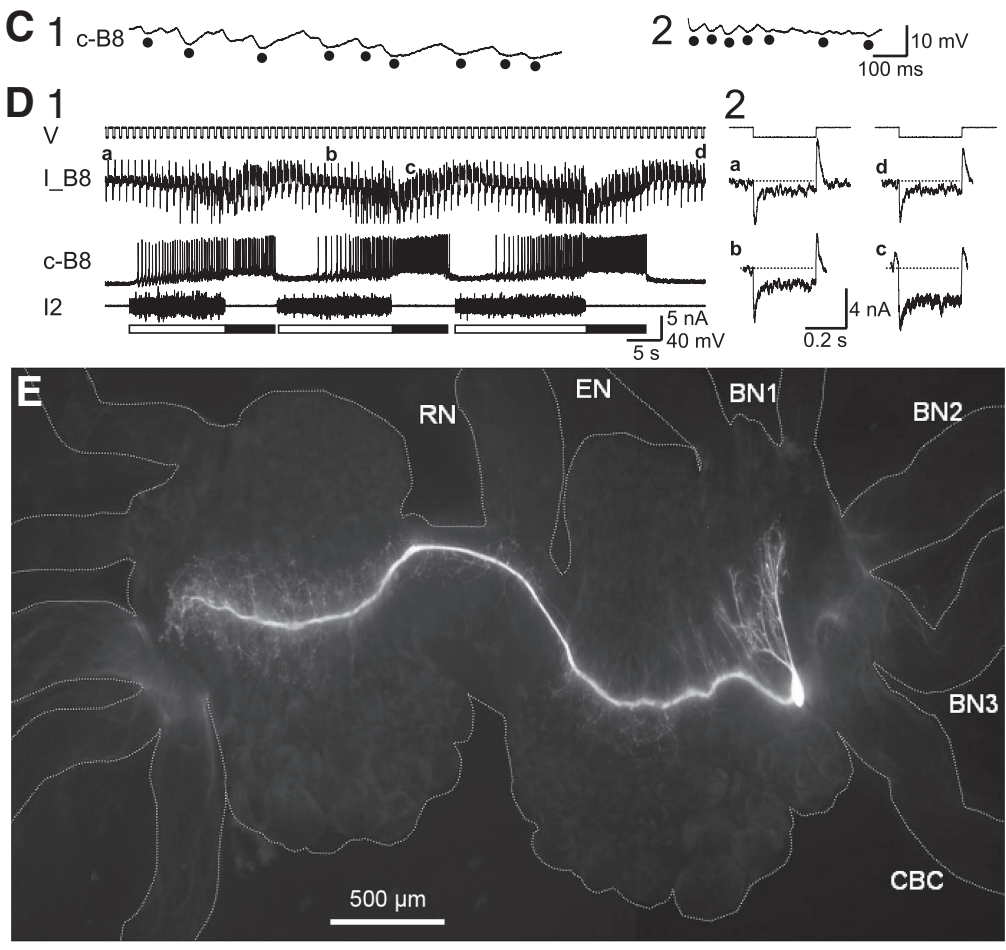

Figure 2. Activity of $B 8, B 4 / 5$, and $B 70$ during feeding motor programs and $B 70$ morphology. $A, B 8$ was strongly active during the retraction phase (filled bars) and weakly active during the protraction phase (open bars) of three ingestive motor program cycles elicited by $\mathrm{CBI}-2$ (A1; $(\mathrm{BI}-2$ record not shown). In contrast, $\mathrm{B} 8$ was active during the protraction of three egestive motor program cycles elicited by EN (A2). Note that both B4/5 and B70 were active during the retraction phase of both types of motor programs. Protraction was monitored by bursting activity in the $\mathrm{I} 2$ nerve, retraction by bursting activity in BN2 that occurred after the termination of protraction. $\boldsymbol{A} \mathbf{1}$ and $\boldsymbol{A} \mathbf{2}$ are from different preparations. $\boldsymbol{B}$, The cycles indicated by the boxes in $\boldsymbol{A}$ enlarged to illustrate the membrane potential depolarization of $B 8$ through the cycle. Dotted line indicates the resting membrane potential of B8. Note the activity of B4/5 and B70 during retraction. C, Portions of the B8 recordings during retraction indicated by the boxes in $\boldsymbol{B}$ further enlarged to illustrate discrete, putative IPSPs (dots) on top of the excitatory input. $\boldsymbol{D}, \mathrm{B} 8$ conductance change during CBI-2-elicited motor programs. B8 was voltage clamped (I_B8 is the recorded current), whereas the contralateral B8 was recorded in current-clamp mode to monitor the program type. Repetitive hyperpolarizing voltage pulses were applied to the voltageclamped B8 (V; $-5.6 \mathrm{mV}, 400 \mathrm{~ms}, 1 \mathrm{~Hz})$. D2, Expanded I_B8 records showing larger currents during protraction (b) and retraction (c) than currents recorded before $(\boldsymbol{a})$ or after $(\boldsymbol{d})$ the programs, indicating increase in B8 conductance. $\boldsymbol{E}$, A dye-filled B70 illustrating its morphology. The main process of B70 projects to the contralateral buccal hemiganglion. Two medium-sized processes that split near the B70 soma ramify in the ipsilateral buccal hemiganglion. The ganglion was slightly distorted because it was placed on a slide with a coverslip. RN, Radula nerve; $C B C$, cerebral-to-buccal connective. " $c$ " before cell names throughout figure legends indicates contralateral. 
$11.77 \pm 0.87 \mathrm{mV}$ in EN-elicited programs $(n=22)$. Inhibitory inputs could then be observed as frequent putative IPSPs on top of the depolarization (Fig. 2C). We also measured changes in $\mathrm{B} 8$ conductance during the motor programs. Initial measurements were done in current-clamp mode by injecting 300-400 ms hyperpolarizing current pulses into B8. Because too much activity (particularly during motor programs) sometimes confounded the measurements, we conducted the rest of the experiments by voltage clamping B8 (Fig. 2D). We found that B8 conductance was increased significantly during both protraction (CBI-2 programs, $248 \%, p<0.01, n=7$; EN programs, $301 \%, p<0.01, n=7)$ and retraction (CBI-2 programs, $654 \%, p<0.01, n=7$; EN programs, $692 \%, p<0.0001, n=7$ ), with larger increases during retraction than during protraction. The conductance increase would have decreased the length constant of B8 and, if the axonal and dendritic processes of B8 were not fully space clamped, would have decreased the area of membrane from which the current was being collected. This should, however, have decreased, rather than increased, the measured current: the conductance increase values that we found were thus probably an underestimate. The conductance increase of $\mathrm{B} 8$ during motor program activity is consistent with findings (Destexhe et al., 2003; Berg et al., 2007) that cortical and spinal neurons receiving concurrent excitation and inhibition exhibit a high-conductance state.

Cortical neurons, particularly in vivo, often fire in a highly irregular manner that has been attributed to the concurrent excitation and inhibition of the neurons (Softky and Koch, 1993; Holt et al., 1996; van Vreeswijk and Sompolinsky, 1996; Destexhe et al., 2003). We therefore examined the regularity of $B 8$ firing in ingestive programs elicited by CBI-2, in which $\mathrm{B} 8$ fired robustly during the retraction phase. (We did not include egestive programs because $\mathrm{B} 8$ activity during retraction was too low.) Specifically, we calculated the coefficient of variation $(\mathrm{CV})$ of the B8 interspike intervals (ISIs) during the retraction phase. For comparison, we also calculated the CV of the ISIs of another motoneuron, $\mathrm{B} 31 / 32$, during the protraction phase (note that $\mathrm{B} 31 / 32$ is hyperpolarized and not active during the retraction phase) (Hurwitz et al., 1996, 1997). We found that the CV for B8 $(0.62 \pm 0.03, n=7)$ was significantly higher $(p<0.001$, twotailed paired $t$ test $)$ than the CV for B31/32 $(0.31 \pm 0.03, n=7)$. The data are consistent with the idea that $\mathrm{B} 8$ receives concurrent excitation and inhibition, whereas B31/32 receives alternating excitation and inhibition, as discussed below (see Fig. 12). In summary, B8 activity during retraction may be determined by a combination of inhibitory and excitatory synaptic inputs that will ultimately determine what type of program is expressed. Here, we will investigate the origin of the inhibitory inputs and seek to elucidate their specific functional role.

\section{Identification and synaptic connectivity of B70}

Previous work has identified two virtually identical multi-action neurons, B4 and B5, as an important source of B8 inhibition during the retraction phase (Gardner, 1971; Rosen et al., 1991; Kabotyanski et al., 1998; Jing and Weiss, 2001; Morgan et al., 2002; Evans et al., 2003b). Here we identify a novel retractionphase interneuron that also inhibits B8. We designated this neuron as B70. There is one B70 in each buccal hemiganglion, and the B70 soma ( $\sim 80 \mu \mathrm{m}$ in diameter $)$ is located on the caudal surface next to B8. Figure $2 E$ illustrates the morphology of a dye-filled $\mathrm{B} 70$ (caudal view) $(n=6)$. Near the soma of B70, there are both major and fine processes that project posteromedially toward the regions in which many of the buccal interneurons, including B34, B40, and B65, are located (Hurwitz et al., 1997; Kabotyanski et al.,

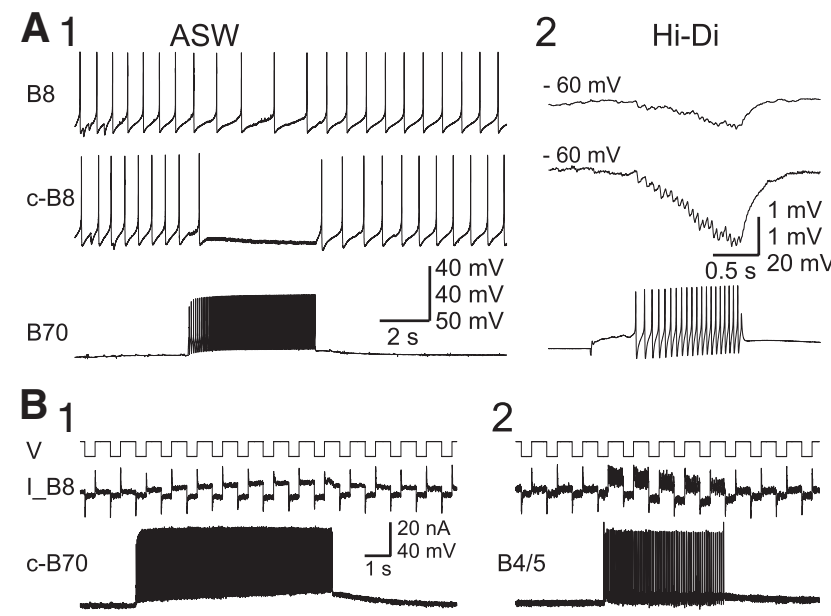

Figure 3. Inhibitory connections from $B 70$ to $B 8$, and $B 8$ conductance increase during stimulation of $B 70$ and $B 4 / 5$. A1, Activation of $B 70$ suppressed the activity of both the contralateral (C-B8) and ipsilateral B8, more so of the former. A2, Activation of B70 elicited fast IPSPs in both the contralateral and ipsilateral $B 8$ that followed the presynaptic $B 70$ spikes one-for-one. Note that the IPSPs were larger in the $c-B 8$ than in the ipsilateral B8. The initial membrane potential of $B 8$ is given on the left. $\boldsymbol{B}$, During activation of $B 70(B 1)$ or B4/5 (B2), larger currents (I_B8) were elicited by repetitive voltage pulses $(\mathrm{V} ;-15 \mathrm{mV}, 400 \mathrm{~ms}$, at $1 \mathrm{~Hz})$ in the voltage-clamped $B 8$, suggesting that the B8 conductance was increased when B70 or B4/5 was stimulated. The recordings in $\mathbf{A} \mathbf{2}$ were made in high-divalent saline (Hi-Di), and all other recordings were in normal saline. ASW, Artificial seawater.

1998; Jing and Weiss, 2002, 2005; Jing et al., 2003; Due et al., 2004). The main axon of $B 70$ projects medially to cross the commissure to the contralateral buccal hemiganglion in which more fine processes can be seen to ramify. The B70 axon was never observed to exit the buccal ganglion through any of the peripheral nerves, indicating that B70 is a true interneuron.

B70 is active during the retraction phase of feeding motor programs no matter whether the programs are ingestive or egestive. Figure $2 \mathrm{~A}$ shows the activity of $\mathrm{B} 70$ in ingestive programs elicited by CBI-2 (Fig. 2A1) and egestive programs elicited by EN (Fig. 2A2). Simultaneous recordings from B4/5 and B70 show that $\mathrm{B} 4 / 5$ and $\mathrm{B} 70$ are both active during the retraction phase of the motor programs. As noted above, B70, like B4/5, inhibits B8. Figure $3 A$ shows representative recordings of the inhibitory connections from B70 to B8. B70 differs from B4/5 in that B70 inhibits $\mathrm{B} 8$ bilaterally and can do so because the B70 axon projects to both buccal hemiganglia, whereas B4/5 only inhibits the ipsilateral $\mathrm{B} 8$ because B4/5 only has axon projections in its ipsilateral buccal hemiganglion. In fact, the inhibitory connection from B70 is stronger to the contralateral B8 than to the ipsilateral B8 (Fig. $3 A 1, A 2$ ). The B70 inhibitory connections appear to be monosynaptic, because they persisted in high-divalent saline, which raises spike threshold and reduces polysynaptic activation. Also, the IPSPs followed the B70 presynaptic spikes one-for-one $(n>6)$ (Fig. 3A2). Because the B8 conductance increased significantly during retraction of motor programs (Fig. $2 D$ ), we asked whether $\mathrm{B} 70$ and $\mathrm{B} 4 / 5$ were among the sources that produced the increase in $\mathrm{B} 8$ conductance. We found that stimulation of $\mathrm{B} 70$ and $\mathrm{B} 4 / 5$ increased B8 conductance (Fig. 3B1,B2) (B70, 269\%, $p<0.001$, $n=9 ; \mathrm{B} 4 / 5,243 \%, p<0.05, n=6)$, suggesting that both $\mathrm{B} 70$ and $\mathrm{B} 4 / 5$ may contribute to the increase in B8 conductance during retraction. From this and the previous work on B4/5, it thus appears that both B4/5 and B70 may function to reduce B8 activity during the retraction phase.

To account for the retraction-phase activity of B70 during motor programs, we examined connections of B70 with both the 
protraction and the retraction neurons of the feeding CPG (Fig. 4). As expected, B70 is inhibited by protraction interneurons such as B63 and B34 (Hurwitz et al., 1997). The connections appear to be monosynaptic because they persisted in high-divalent saline and followed the presynaptic spikes one-for-one $(n>6)$ (Fig. $4 A)$. These inhibitory connections may contribute to the absence of activity of B70 during the protraction phase. No reciprocal connections from B70 to B63 or B34 were observed.

In addition, $\mathrm{B} 70$ is electrically coupled to its contralateral homolog (Fig. 4B), with a steady-state coupling ratio of $0.0375 \pm 0.008(n=5)$. Moreover, consistent with the normal activity of B70 during the retraction phase, B70 is electrically coupled to several retraction-phase neurons, including B64, B51, and B21 (Plummer and Kirk, 1990; Hurwitz and Susswein, 1996; Evans and Cropper, 1998; Rosen et al., 2000; Evans et al., 2003a; Jing et al., 2004) (Fig. 4C). Furthermore, B70 is electrically coupled to both the ipsilateral and the contralateral B4/5 (Fig. 4C). We calculated the steady-state coupling ratio between B70 and the contralateral B4/5. We found that the coupling is stronger from B4/5 to B70 than from B70 to B4/5: the steady-state coupling ratio from $\mathrm{B} 4 / 5$ to B70 was $0.044 \pm 0.01(n=5)$, and, from B70 to B4/5, it was $0.014 \pm 0.004$ $(n=7)$. In addition to the electrical coupling, B70 may also have chemical synapses that excite B4/5 and inhibit B51 and B21 (Fig. 4D). Conversely, B64 and B21 may have chemical synapses that excite B70, whereas B4/5 may inhibit B70 (Fig. 4E). Note that, because of the electrical coupling, the inhibitory connections from B70 to B51 and B21 (Fig. 4D2) and from B4/5 to B70 (Fig. 4E2) became obvious only when the presynaptic neuron was fired at higher frequency so as to override the electrical coupling. These activity and connectivity properties of B70 support the notion that $\mathrm{B} 70$, like $\mathrm{B} 4 / 5$, is an integral member of the feeding CPG.

\section{Inhibitory control of B8 retraction-phase activity by B4/5 and B70}

B8 activity during retraction is an important indicator of how ingestive the motor programs are: higher $\mathrm{B} 8$ activity during retraction suggests a more ingestive program (Figs. 1, 2A). Previous work (Kabotyanski et al., 1998; Jing and Weiss, 2001; Evans et al., 2003b) suggested that $\mathrm{B} 4 / 5$ is more active during egestive programs than ingestive programs and may suppress the retraction-phase activity of B8, thereby making the motor programs more egestive. This raised the question whether $\mathrm{B} 70$, too, may be more active during the retraction phase of egestive programs and thereby contribute to their egestiveness. To examine this possibility quantitatively, we defined a linear ingestiveness index for the motor programs, with 1 denoting the most ingestive and -1 the most egestive program (see Materials and Methods, Fig. 1). We then calculated the correlation coefficient (Pearson's $r$ ) between the ingestiveness index of CBI-2-elicited programs and B4/5 or B70 activity during retraction. The correlation coefficient between the ingestiveness index and B4/5 activity was -0.675 (Fig. $5 A$, top) $\left(r^{2}=0.456\right.$, $p<0.0001, n=329)$, whereas between the ingestiveness index and B70 activity, it was -0.643 (Fig. $5 A$, bottom) $\left(r^{2}=0.413, p<\right.$ $0.0001, n=468)$. Thus, both B $4 / 5$ and B70 activity was inversely correlated with the ingestiveness index. Consistent with this, the B4/5 and B70 activities were positively correlated (Fig. 5B) $(r=$ 0.605, $\left.r^{2}=0.367, p<0.0001, n=329\right)$. It is notable, however, that when $\mathrm{B} 4 / 5$ and $\mathrm{B} 70$ were active at moderate rates $(<15 \mathrm{~Hz})$, there were instances in which B4/5 and B70 showed differential activity, i.e., one being active whereas the other was weakly active. Figure $5 C$ shows two such examples. Interestingly, this differential activity of B4/5 and B70 was associated with different B8 activity during retraction (see below): when $\mathrm{B} 4 / 5$ was more active, B8 was more active during the later part of retraction (Fig. 5C1), and when $\mathrm{B} 70$ was more active, $\mathrm{B} 8$ was more active during the early part of retraction (Fig. 5C2).

These data suggest that the activity of the radula closing motoneuron B8 during a single program phase, retraction, is under the inhibitory control of two neurons, B4/5 and B70. The issue now is whether the inhibitory effects of B4/5 and B70 are simply additive or whether they can be differentiated functionally (compare Fig. 5C). To determine this, we first examined more closely the temporal profiles of the activity of B4/5 and B70 during the retraction phase. Indeed, previous work has suggested that B4/5 fires most strongly during the early part of retraction, and its activity tends to decline toward the end of retraction (Evans et al., 2003b). 

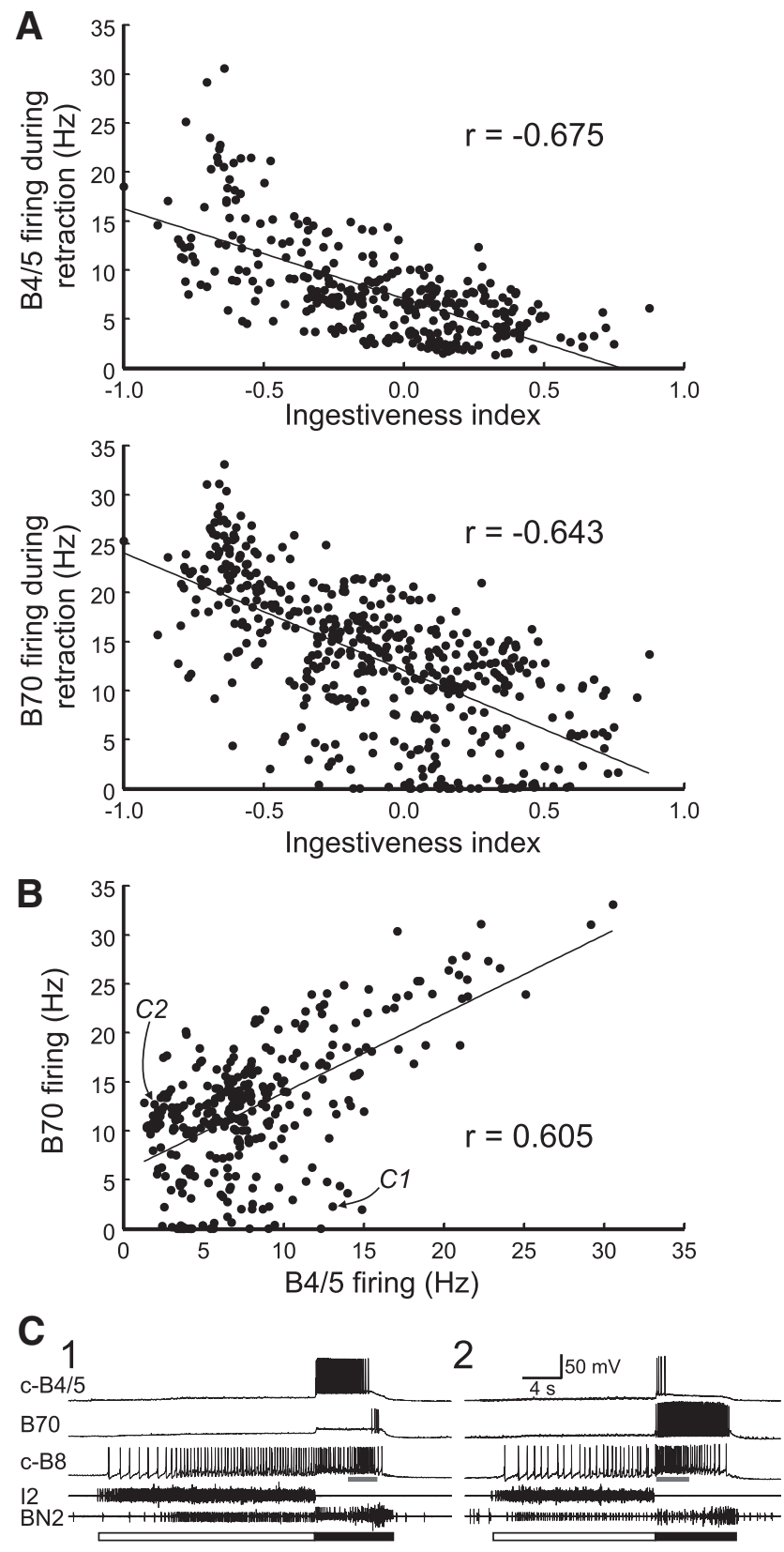

Figure 5. Retraction-phase activities of $B 4 / 5$ and $B 70$ are inversely correlated with the degree of ingestiveness of the motor programs. $A$, Plot of ingestiveness index against retraction-phase B4/5 (top) or B70 (bottom) activity, showing inverse correlations. $B$, Plot of retraction-phase $B 4 / 5$ activity against retraction-phase $B 70$ activity, showing a positive correlation. Note the broad distribution of the $B 4 / 5$ and $B 70$ activities at low frequencies $(<15 \mathrm{~Hz})$; there are numerous instances of differential activity of $B 4 / 5$ versus $B 70$, when one is active but the other is not. Lines, Linear regression lines; $r$, correlation coefficient. C 1 and $C 2$ in the plot correspond to the examples shown in C. C, Differential activity of B4/5 versus B70 in two motor program cycles elicited by $\mathrm{CBI}-2$. C1, High B4/5 activity with low B70 activity was associated with higher B8 activity during the later part of retraction (gray bar). C2, High B70 activity with low B4/5 activity was associated with higher B8 activity during the early part of retraction (gray bar). $\mathbf{C}$ and $\mathbf{C}$ are from different preparations.

To obtain a quantitative analysis of B4/5 and B70 activity during retraction, we elicited motor programs by stimulating CBI-2 and simultaneously recorded the activities of B4/5, B70, and B8 (for examples, see Figs. 2A1, 5C). For each program cycle, we divided the retraction phase into 10 equal time bins and calculated the frequencies of B4/5, B70, and B8 during each bin. Figure $6 \mathrm{~A}$ shows the data from 329 program cycles from 10 prepara-
A
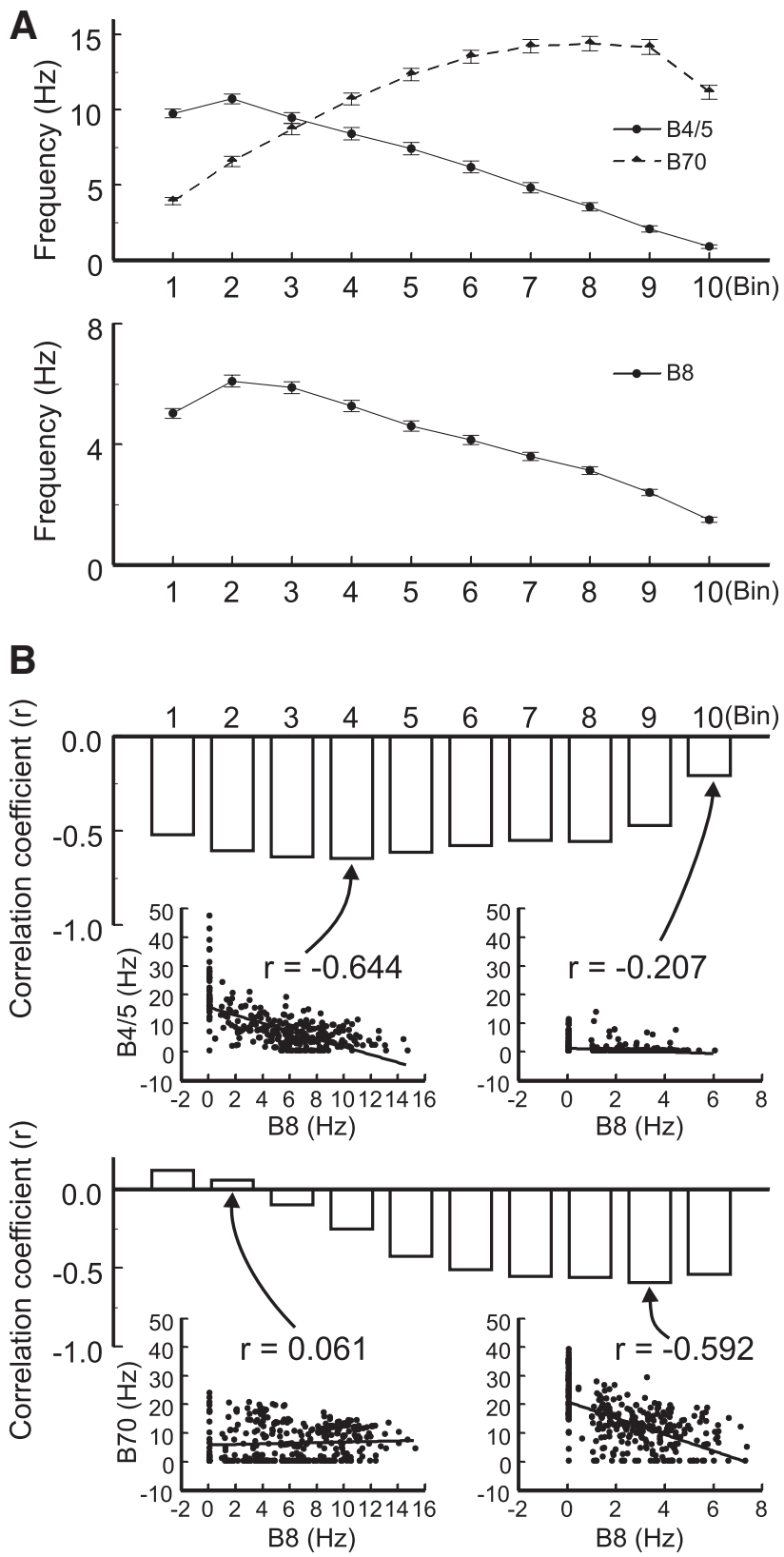

Figure 6. Temporal profiles and correlations of $B 8, B 4 / 5$, and $B 70$ activity. $A$, Temporal profiles of activity of $B 4 / 5, B 70$, and $B 8$ throughout retraction. Simultaneous recordings from $B 4 / 5, B 70$, and $B 8$ were made during motor programs elicited by $\mathrm{CBI}-2$. Retraction was divided into 10 time bins, the spikes of each neuron in each bin were counted, and the average firing frequency in each bin was determined. The graphs show that $B 4 / 5$ activity gradually decreased, whereas $B 70$ activity increased, as retraction progressed. $B$, Correlation coefficient $(r)$ between B8 and B4/5 activity (top) or B8 and B70 activity (bottom) during each time bin. For B4/5, the correlation coefficient was more negative in earlier than later bins, whereas for $B 70$ the converse. For $B 4 / 5, p<0.0001$, except for bin $10, p<0.001$; for $B 70$, bin $1, p<0.05$, bins $2-3$, $p>0.05$, bins $4-10, p<0.0001$. The four insets show examples of the plots of $B 8$ versus $B 4 / 5$ activity (top) or B8 versus B70 activity (bottom) in the individual bins indicated. Lines in the insets indicate linear regression lines. Error bars indicate SEM.

tions. All program types, ingestive, egestive, and intermediate, were included. On average, B4/5 activity peaked during the second bin and then gradually declined as retraction progressed $\left(F_{(9,2952)}=384.6, p<0.0001\right.$; post hoc test with Bonferroni's correction: bin 2 is significantly different from bin $1, p<0.01$, and is significantly different from bins $3-10, p<0.001$ ), confirming the previous findings (Evans et al., 2003b). B70, however, 
showed the opposite activity pattern $\left(F_{(9,2952)}=225.6, p<0.0001\right)$. Specifically, B70 activity was lowest in the first bin and then gradually increased as retraction progressed ( post hoc test with Bonferroni's correction: bin 1 is significantly different from bins 2-10, $p<0.001$ ); it peaked in bins 7-9 and then decreased slightly to bin 10 . Thus, the data suggest that, although both $\mathrm{B} 4 / 5$ and $\mathrm{B} 70$ are active during retraction, B4/5 may be preferentially active during the early part of retraction, whereas $\mathrm{B} 70$ may be preferentially active during the late part. The increase in B70 activity during the late part of retraction may account at least partly for the decline of B8 activity during that time.

To further analyze the relationship between the activities of B4/5 and B70 and the activity of B8, we plotted the activity of B4/5 or B70 against the activity of B8 during each time bin (examples are shown in the four insets in Fig. $6 \mathrm{~B}$ ) and performed correlation analysis (Fig. 6B). For B4/5, the correlation coefficient was the most negative (less than -0.6) in bins 2-5, showing that B8 activity was inversely correlated with B4/5 activity in these bins. The correlation coefficient became progressively less negative in later bins and was close to 0 in bin 10 . In contrast, for B70 the correlation coefficient was close to 0 in bins $1-3$ and then became progressively more negative to peak in bin $9(r=-0.592)$. Thus, B70 activity was inversely correlated with B8 activity in the later bins. The data are consistent with the idea that B4/5 may have a more significant inhibitory effect on B8 activity during the early part of retraction and B70 during the late part.

To obtain direct evidence that B70 activity may in fact function to reduce retraction-phase B8 activity in motor programs elicited by CBI-2, we performed B70 hyperpolarization experiments. Because B70 elicits larger-amplitude IPSPs in the contralateral B8 than the ipsilateral B8 (Fig. 3), we examined the contralateral B8 in these experiments. Figure $7 A$ shows a representative example of one such experiment. In the motor program elicited by CBI-2 under control condition (Fig. 7A1), the $\mathrm{B} 8$ activity was moderate during both protraction and retraction, indicating an intermediate program. When B70 was hyperpolarized (Fig. 7A2), the $\mathrm{B} 8$ activity increased during retraction (Fig. $7 B, C$ ) but did not obviously change during protraction. Thus, the program became more ingestive. The group data $(n=15)$ in Figure $7 D$ show that, when $\mathrm{B} 70$ was hyperpolarized, the $\mathrm{B} 8$ activity during protraction did not change significantly $(p>0.05)$ (Fig. 7D1), whereas during retraction, it was significantly increased $\left(F_{(2,28)}=56.4\right.$, $p<0.0001$ ) (Fig. 7D2). Furthermore, we measured the peak baseline depolarization of $\mathrm{B} 8$ during the second half of retraction (Fig. 7C, dotted lines) and found that, when B70 was hyperpolarized, the depolarization increased significantly $\left(F_{(2,28)}=41.54\right.$, $p<0.0001$ ) (Fig. 7D3), supporting the idea that B70 inhibition acts to counter the excitatory inputs to B8.

In Figure $6 B$, we provided correlational evidence that B70 acts primarily in the later part of the retraction phase. The hyperpolarization of B70 might therefore be effective primarily at that time. To determine whether this is the case, we divided the B70 hyperpolarization data that was used in Figure 7D2 into 10 time bins and performed a two-way ANOVA (Fig. 7E). The two factors were the time binning and the presence or absence of the B70 hyperpolarization. The effects of both factors were significant (binning, $F_{(9,280)}=5.56, p<0.0001$; B70 hyperpolarization, $\left.F_{(2,280)}=116.1, p<0.0001\right)$. The interaction between the two factors was also significant $\left(F_{(18,280)}=4.76, p<0.0001\right)$. Consistent with our hypothesis, Bonferroni's post hoc tests showed that effects of B70 hyperpolarization were significant during later bins (bins 4-10) but not during bins 1-3. 

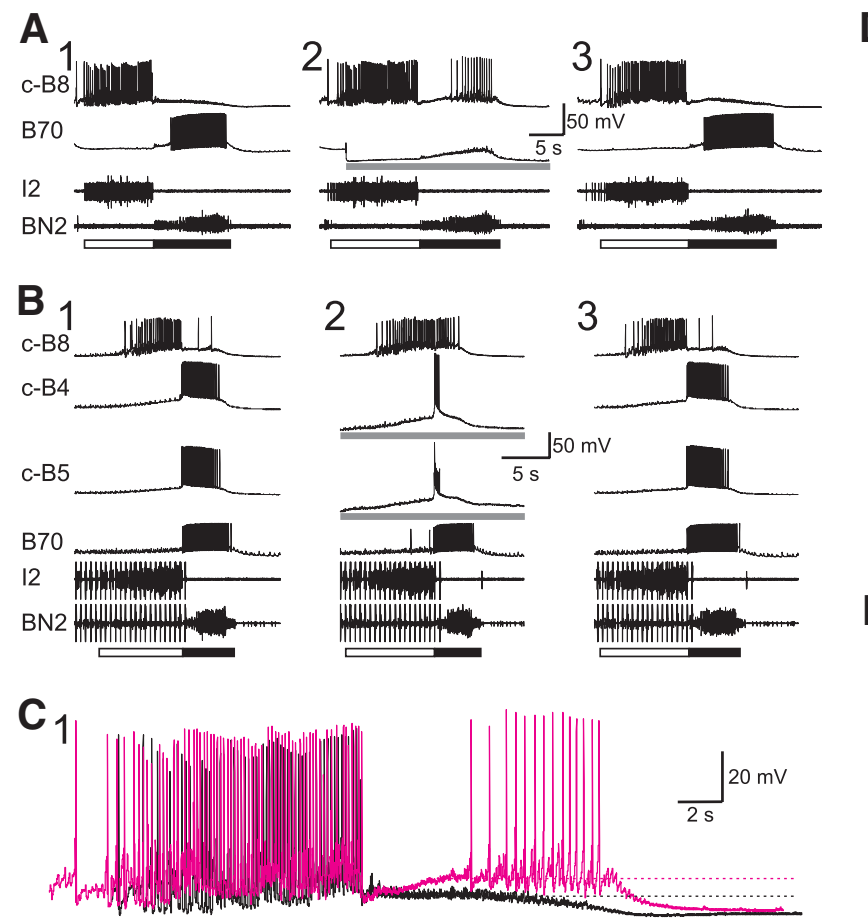

2
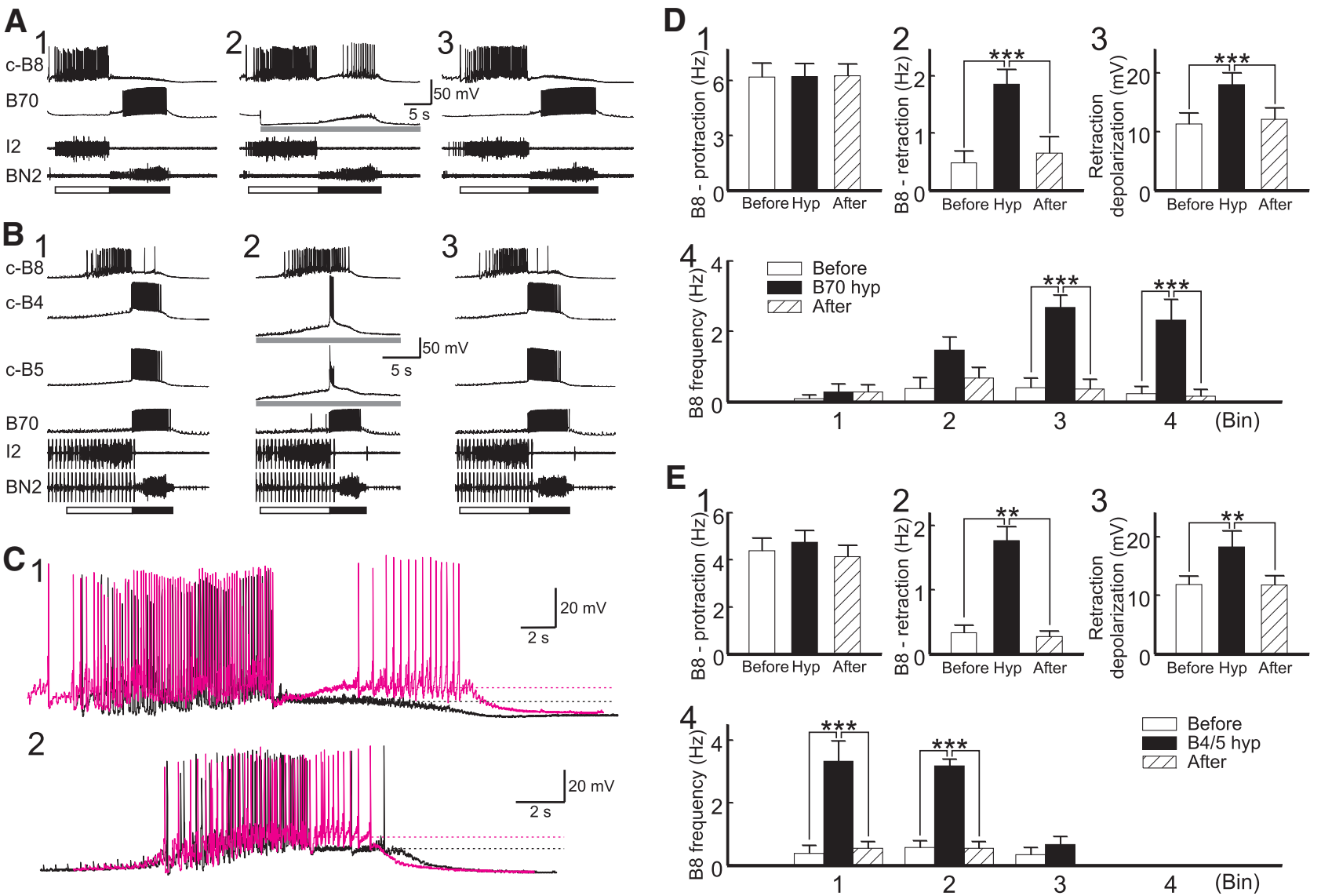

Figure 8. Hyperpolarization of $B 70$ and $B 4 / 5$ increases, respectively, the late and early retraction-phase activity of $B 8$ in EN-elicited programs. $A, B$, Stimulation of EN elicited egestive programs, in which $B 8$ was active during protraction $(\boldsymbol{A} \mathbf{1}, \boldsymbol{B} 1)$. When $B 70(\boldsymbol{A 2})$ or $B 4$ and $B 5(B 2)$ were hyperpolarized (gray bars), the activity of $B 8$ increased during retraction. Note that, when $B 4$ and $B 5$ were hyperpolarized (B2), B70 remained active. $\boldsymbol{A} \mathbf{3}, \boldsymbol{B} 3$, Subsequent programs returned to control activity. $\boldsymbol{C}$, Expanded B8 records from $\boldsymbol{A} \mathbf{1}$ (black) and $\boldsymbol{A 2}$ (red) (C1), or $\boldsymbol{B} \mathbf{1}$ (black) and $\boldsymbol{B} \mathbf{2}$ (red) (C2), show more depolarized baseline membrane potential of $B 8$ during retraction when $B 70(C 1)$ or $B 4 / 5(C 2)$ was hyperpolarized. The dotted lines indicate the baseline depolarization of $B 8$ during retraction in each case. $\boldsymbol{D}, \boldsymbol{E}$, Group data showing the effects of $B 70$ or $B 4 / 5$ hyperpolarization (Hyp) on the B8 activity during protraction (D1, B70; E1, B4/5), the B8 activity during retraction (D2, B70; E2, B4/5), and the baseline depolarization of $B 8$ during retraction $(D 3, B 70 ; E 3, B 4 / 5)$. D4, E4, Group data showing the effects of $B 70(D 4)$ or $B 4 / 5(E 4)$ hyperpolarization on the $B 8$ activity when the retraction was divided into four time bins. The B70 hyperpolarization had significant effects on B8 activity in later bins (D4), whereas the B4/5 hyperpolarization had significant effects in earlier bins (E4). Bonferroni's post hoc tests: ${ }^{* *} p<0.01 ;{ }^{* *} p<0.001$. Error bars indicate SEM.

In addition, we examined the effect of $B 70$ hyperpolarization on motor programs elicited by EN stimulation (Fig. $8 \mathrm{~A}$ ). ENelicited programs are mostly egestive (Fig. 2A2) (Chiel et al., 1986; Morton and Chiel, 1993b; Morgan et al., 2002; Proekt et al., 2004, 2007). More importantly, EN programs allowed us to perform similar hyperpolarization experiments with B4/5 (Fig. 8 B) and compare the effects of B70 and B4/5 hyperpolarization, because the activities of both B70 and B4/5 were consistently high in these egestive-like programs. In the representative example in Figure $8 A$, the control motor program (Fig. $8 A 1$ ) was egestive, because $B 8$ fired strongly during the protraction phase but not during the retraction phase. Furthermore, B70 fired strongly during retraction. When $\mathrm{B} 70$ was hyperpolarized (Fig. 8 A2), the B8 activity during retraction, particularly during the later part of the retraction phase, increased. Subsequent programs returned to the control activity (Fig. $8 A 3)$. Group data $(n=7)$ showed that, when $\mathrm{B} 70$ was hyperpolarized, the $\mathrm{B} 8$ activity did not change significantly during protraction (Fig. $8 D 1)\left(F_{(2,12)}=0.14, p>\right.$ $0.05)$ but significantly increased during retraction (Fig. $8 D 2$ ) $\left(F_{(2,12)}=26.52, p<0.0001\right)$. Moreover, the baseline membrane depolarization of B8 (Fig. 8C1, dotted lines) increased significantly (Fig. 8D3) $\left(F_{(2,12)}=26.52, p<0.0001\right)$. Similar experiments with B4/5 (Fig. $8 B$ ) showed that B4/5 hyperpolarization
( $n=4)$, likewise, had no significant effect on the B8 activity during protraction (Fig. 8E1) $\left(F_{(2,6)}=2.94, p>0.05\right)$, but it had a significant effect on the $\mathrm{B} 8$ activity during retraction (Fig. $8 E 2$ ) $\left(F_{(2,6)}=36.49, p<0.001\right)$ and on the baseline B8 depolarization (Fig. 8E3) $\left(F_{(2,6)}=19.84, p<0.01\right)$. This is consistent with previous work showing that hyperpolarization of a single B4/5 affects B8 activity in spontaneously generated egestive programs (Kabotyanski et al., 1998).

The representative examples of B70 and B4/5 hyperpolarization in Figure 8 appear to show that the retraction-phase B8 activity is increased more in the later part of retraction when B70 is hyperpolarized (Fig. $8 \mathrm{~A} 2$ ), and more in the early part of retraction when B4/5 is hyperpolarized (Fig. 8 B2). To evaluate these effects quantitatively, we again divided the B8 activity during retraction into time bins. However, because in these programs the $\mathrm{B} 8$ activity was relatively low during retraction (compare the B8 activity in the CBI-2 programs in Fig. 7), we divided the retraction into 4 bins instead of 10 bins. The group data are shown in Figure 8, D4 and E4. We performed two-way ANOVA on these data. For B70 hyperpolarization (Fig. 8D4), the effects of the two factors, binning and hyperpolarization, were both significant (binning, $F_{(3,48)}=3.11, p<0.05$; B70 hyperpolarization, $F_{(2,48)}=46.09$, $p<0.0001)$. The interaction between the two factors was also signif- 
A

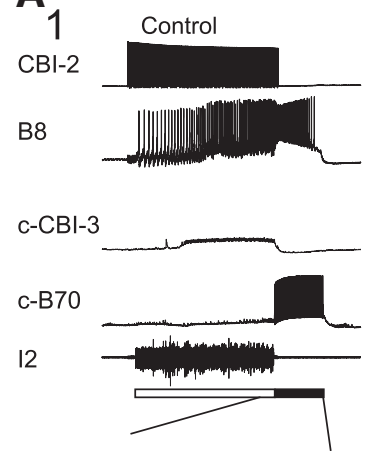

B

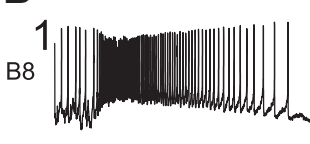

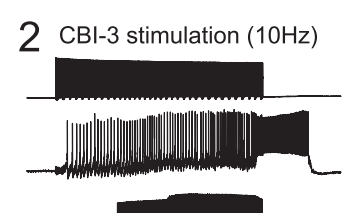

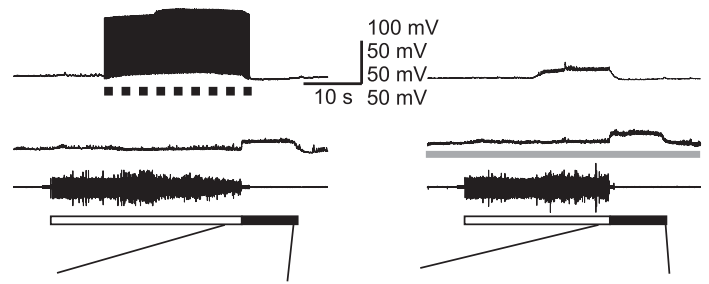

$\sim$

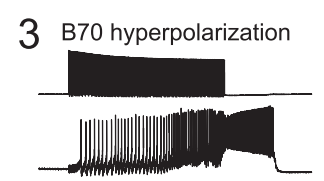

3 B70 hyperpolarization
C
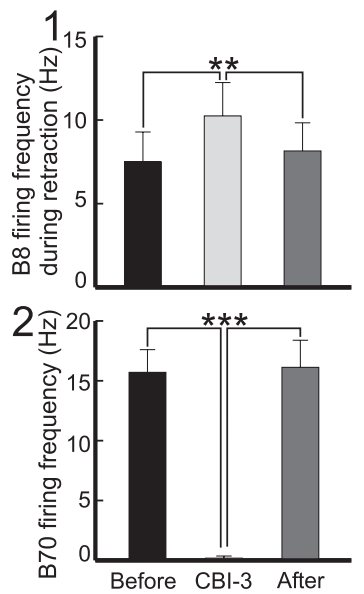

Figure 9. $\mathrm{CBI}-3$ increases the activity of $\mathrm{B} 8$ in retraction partly by inhibiting $\mathrm{B} 70$. $\boldsymbol{A}$ 1, $\mathrm{A}$ control program elicited by stimulation of $\mathrm{CBI}-2$ at $10 \mathrm{~Hz}$. The $\mathrm{CBI}-3$ ipsilateral to $\mathrm{B} 70$ ( $\mathrm{C}-\mathrm{CBI}-3)$ was hyperpolarized to prevent it from firing. $\mathbf{A 2}$, $\mathrm{C}-\mathrm{CBI}-3$ was costimulated with $\mathrm{CBI}-2$ at $10 \mathrm{~Hz}$ (dotted line), eliminating the $\mathrm{B} 70$ activity and increasing the retraction-phase $\mathrm{B} 8$ activity. $\mathbf{A} \mathbf{3}, \mathrm{B} 70$ was

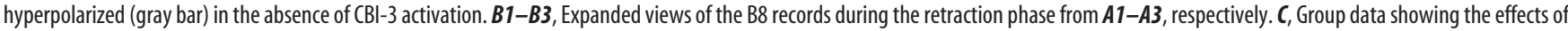
CBI-3 stimulation (CBI-3) on the retraction-phase activities of $\mathrm{B} 8(C 1 ; n=5)$ and $B 70(C 2 ; n=5)$. Bonferroni's post hoc tests: ${ }^{* *} p<0.01 ;{ }^{* * *} p<0.001$. Error bars indicate SEM.

icant $\left(F_{(6,48)}=6.8, p<0.0001\right)$. Bonferroni's post hoc tests showed that the effects of $\mathrm{B} 70$ hyperpolarization were significant during the later bins (bins 3 and $4, p<0.001$ ) but not during the first two bins. Similarly, for B4/5 hyperpolarization (Fig. 8 E4), the effects of the two factors, binning and hyperpolarization, were both significant (binning, $F_{(3,24)}=25.54, p<0.0001$; B $4 / 5$ hyperpolarization, $\left.F_{(2,24)}=50.81, p<0.0001\right)$. The interaction between the two factors was also significant $\left(F_{(6,24)}=12.27, p<0.0001\right)$, and, in contrast to the B70 hyperpolarization, Bonferroni's post hoc tests showed that the effects of B4/5 hyperpolarization were significant during the earlier bins (bins 1 and 2, $p<0.001$ ) but not the last two bins.

These findings indicate that both B4/5 and B70 function to reduce $\mathrm{B} 8$ activity during retraction, thereby contributing to the egestiveness of motor programs. Furthermore, the actions of B4/5 and $\mathrm{B} 70$ are complementary in that $\mathrm{B} 4 / 5$ acts on $\mathrm{B} 8$ preferentially in the early part of retraction and B70 in the later part of retraction.

\section{Regulation of B70 activity by ingestion-promoting peptidergic interneuron $\mathrm{CBI}-3$}

Previous work has shown that activity of the higher-order modulatory interneuron CBI-3 acts to increase the ingestiveness of the motor programs. In part, this action of CBI-3 is brought about by its slow inhibition of the retraction-phase activity of neurons B4/5 (Jing and Weiss, 2001; Morgan et al., 2002). Our findings here that $\mathrm{B} 4 / 5$ and $\mathrm{B} 70$ are more active in egestive programs than ingestive programs (Fig. 5), and that B70 acts in conjunction with B4/5 to suppress the retraction-phase activity of B8 (Figs. $6-8$ ) raise the possibility that CBI-3 may also suppress the activity of B70 to promote more ingestive programs. In particular, in view of the fact that B70 is preferentially active during the later part of retraction, it is important to determine whether the possible slow inhibition by CBI-3 persists long enough to be still effective on B70.

We first sought to determine whether B70 activity was different when we stimulated CBI-2 alone or stimulated CBI-2 together with CBI-3. One example is shown in Figure 9, $A$ and $B$. When CBI-2 was stimulated alone, $\mathrm{B} 70$ fired at a robust rate (Fig. 9A1). However, when CBI-3 was coactivated at $10 \mathrm{~Hz}$ with CBI-2,
B70 no longer fired, and, concomitantly, the firing of B8 during retraction also increased (Fig. 9A2,B2). We also hyperpolarized B70 directly, whereupon the B8 activity also increased but to a somewhat lesser degree than when CBI-3 was stimulated (Fig. $9 A 3, B 3)$. The group data show that, during the CBI-3 stimulation, the activity of B70 was almost completely eliminated (Fig. 9C2) $\left(F_{(2,8)}=44.36, p<0.0001, n=5\right)$, whereas the activity of B8 increased significantly (Fig. 9C1) $\left(F_{(2,8)}=19.85\right.$; $p<0.001)$. On average, B8 activity during retraction increased to $136 \pm 6.9 \%$ with CBI- 3 stimulation and to $122 \pm 4.7 \%$ with B70 hyperpolarization $(n=5)$. The effect of the CBI-3 stimulation was only marginally larger than that of the B70 hyperpolarization, but the difference was statistically significant $(p<0.05)$. This is likely to be attributable to the fact that CBI-3 reduces also the activity of B4/5 (Jing and Weiss, 2001; Morgan et al., 2002).

We then examined whether CBI-3 stimulation had a direct inhibitory effect on B70 excitability. In these experiments, we stimulated B70 with $2.5 \mathrm{~s}$ depolarizing current pulses every $60 \mathrm{~s}$ to elicit $\sim 18$ B70 spikes during each depolarization. In selected trials, we stimulated CBI-3 at various frequencies $(3,5$, and $10 \mathrm{~Hz})$ for $5 \mathrm{~s}$ immediately before the depolarization of B70, a paradigm mimicking the normal firing pattern of CBI-3 (in protraction) and B70 (in retraction, which follows protraction) (Jing and Weiss, 2001). Under these conditions, the CBI-3 stimulation reduced the excitability of $\mathrm{B} 70$ (Fig. $10 \mathrm{~A}$ ). The group data $(n=4)$ show that the CBI-3 stimulation reduced the B70 excitability in a frequency-dependent manner (Fig. 10 B) (3 $\mathrm{Hz}, F_{(2,6)}=9.3, p<0.02 ; 5 \mathrm{~Hz}, F_{(2,6)}=64.0, p<0.0001 ; 10$ $\left.\mathrm{Hz}, F_{(2,6)}=199.6, p<0.0001\right)$.

CBI-3 is a peptidergic interneuron that contains the peptide APGWamide (Morgan et al., 2002), which appears to mediate inhibitory actions of CBI-3 on B4/5 (Jing and Weiss, 2001). We therefore examined whether APGWamide had a similar effect on B70. We first determined the direct effects of APGWamide on the excitability of B70. We found that APGWamide reduced the B70 excitability in a concentration-dependent manner (Fig. $10 C, D)\left(F_{(4,16)}=47.4, p<0.0001, n=5\right)$. Notably, the APGWamide concentration that began to inhibit B70 excitability 

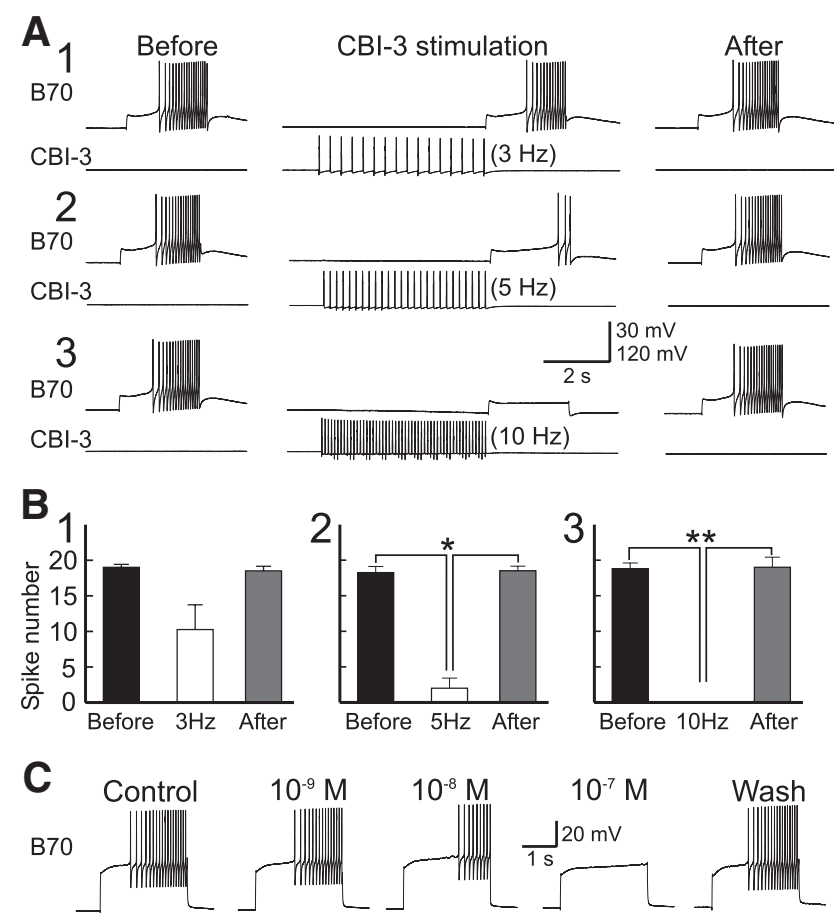

D
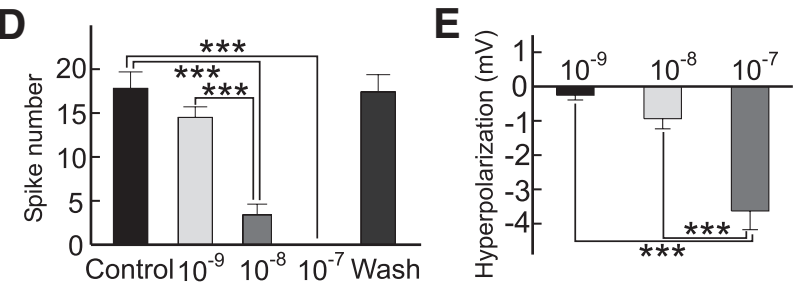

Figure 10. $\quad(B I-3$ and its peptide, APGWamide, inhibit $B 70$ excitability. $A, B$, Effects of $C B I-3$. $A$, Representative examples. Depolarizing current pulses, $2.5 \mathrm{~s}$ long, were injected into $B 70$ every $60 \mathrm{~s}$. (BI- 3 was stimulated with brief current pulses at $3 \mathrm{~Hz}(\boldsymbol{A} \mathbf{1}), 5 \mathrm{~Hz}(\boldsymbol{A 2})$, and $10 \mathrm{~Hz}(\boldsymbol{A} \mathbf{3})$ for $5 \mathrm{~s}$ before the $B 70$ depolarization. The firing of $\mathrm{CBI}-3$ reduced the number of $B 70$ spikes in a frequency-dependent manner. $\boldsymbol{B}$, Group data. $\boldsymbol{B} 1-B \mathbf{3}$ correspond to $\boldsymbol{A} \mathbf{1}-\mathbf{A} \mathbf{3}$, respectively. $\boldsymbol{C}-\boldsymbol{E}$, Effects of APGWamide. $\boldsymbol{C}$, Representative examples. Depolarizing current pulses were injected into B70 every $25 \mathrm{~s}$. APGWamide was applied in ascending concentrations from $10^{-9}$ to $10^{-7} \mathrm{M}$. The application of APGWamide reduced the number of B70 spikes in a concentration-dependent manner. B70 spiking recovered after washout of the peptide. $\boldsymbol{D}$, Group data for the effect of APGWamide on the number of spikes in B70. Some comparisons are not shown for clarity: Bonferroni's post hoc tests between wash and $10^{-9} \mathrm{M}, p>0.05$; between wash and $10^{-8}$ or $10^{-7} \mathrm{M}, p<0.001$. $E$, Group data for the APGWamide-induced hyperpolarization of B70. All recordings were made in high-divalent saline. Bonferroni's post hoc tests: ${ }^{*} p<0.05 ;{ }^{* *} p<0.01 ;{ }^{* * *} p<0.001$. Error bars indicate SEM.

was quite low, $\sim 10^{-9}$ M. Furthermore, we also found that APGWamide hyperpolarized B70 in a concentration-dependent manner (Fig. $10 E)\left(F_{(2,8)}=63.07, p<0.0001, n=5\right)$, consistent with the reduction of excitability.

In the next series of experiments, we examined whether APGWamide could occlude the CBI-3 inhibition of B70. Under control condition, CBI-3 stimulation suppressed B70 excitability (Fig. 11 A1), but when we perfused $10^{-7} \mathrm{M}$ APGWamide, this was no longer the case (Fig. 11A2). (Because APGWamide inhibited the B70 excitability, when APGWamide was applied, we increased the amplitude of the depolarizing current pulses injected into B70 so as to continue to elicit $\sim 18$ B70 spikes.) The group data $(n=4)$ show that the B70 excitability after CBI-3 stimulation under control, APGW, and wash conditions was significantly different $($ Fig. $11 B)\left(F_{(2,6)}=152.4, p<0.0001\right)$. Individual comparisons with Bonferroni's corrections showed that the
APGWamide group was significantly different from the control and wash groups $(p<0.001)$, but the control and wash groups were not significantly different from each other $(p>0.05)$. To gain additional insight into the possibility that the actions of CBI-3 may be mediated by APGWamide, we characterized the synaptic connection between $\mathrm{CBI}-3$ and B70 and then attempted to occlude the synaptic potentials from CBI-3 to B70 with APGWamide. In high-divalent solution, CBI-3 elicits in B70 a complex IPSP whose multiple components have different time courses. We found that APGWamide occluded the two slower components of the complex IPSP (Fig. 11C). Together with the previous work with B4/5 (Jing and Weiss, 2001), these data suggest that CBI-3 may promote more ingestive programs by suppressing the activities of both B4/5 and B70 and that these suppressive actions may be mediated at least in part by the persistent actions of the APGWamide peptide that CBI-3 contains. More importantly, the slow peptidergic inhibition by CBI-3 persists long enough to be effective on both B4/5 and B70.

\section{Discussion}

Partly because of its prevalence in cortical networks (Destexhe et al., 2003), network control by concurrent excitation and inhibition has attracted significant attention. Recently, this form of control was also found in spinal motor networks (Berg et al., 2007) and in the leech local bending network (Baca et al., 2008). In general, this control mechanism may be important for such network functions as enhanced responsiveness or gain control. In spinal motor networks, this mechanism may function to randomize the timing of spikes (Berg et al., 2007) and to increase the temporal resolution of spinal motoneurons (Alaburda et al., 2005; Berg et al., 2008).

Here we investigated how concurrent excitation and inhibition might control the activity of output neurons during the generation of multiple motor programs. We demonstrated a complexity of the inhibitory control that would not be apparent without identifying the inhibitory neurons. Specifically, the inhibition was exerted by two types of neurons that are active during the same phase of the motor programs yet do not simply function additively. Instead, these inhibitory neurons exert temporally specific control of the activity of the output neurons.

Motor systems that generate multiple sets of agonist and antagonist muscle movements are often multifunctional, that is, they have the ability to generate multiple forms of behavior. Work in both vertebrates and invertebrates (Stein and Smith, 1997; Orlovsky et al., 1999; Jing et al., 2004) indicates that multifunctionality depends on the ability of CPG networks to change the phasing of some sets of movements while maintaining stable phase relationship of other sets of movements. Thus, in the generation of different forms of behavior, one set of agonist and antagonist motoneurons and muscles may have a stable, fixed alternating phase relationship, whereas other sets may exhibit variable phase relationships relative to the stable set, as have been observed in the feeding systems of Aplysia (Morton and Chiel, 1993a,b; Jing and Weiss, 2002) and lobster (Combes et al., 1999), turtle scratching (Mortin et al., 1985; Berkowitz and Stein, 1994), and cat hindlimb movements (Smith et al., 1998; Orlovsky et al., 1999). Importantly, additional forms of behavior may involve double bursts of activity of motoneurons within a single program cycle (Rossignol, 1996).

How are the stable, or variable, relationships of the rhythmic activity of motoneurons and muscles produced by the CPG interneurons? An answer to this question requires an understanding of how CPGs use excitation and inhibition to 
generate rhythmic activity. For this, two models have been proposed. In the classical half-center model (Brown, 1911), excitation and inhibition alternate (Fig. $12 \mathrm{~A} 1)$ so that motoneurons are active with their excitatory interneurons but terminate firing when their inhibitory neurons become active. In a second model, excitation and inhibition are concurrent (Fig. 12A2), and motoneuronal activity is determined by the relative levels of excitation and inhibition that the motoneurons receive. In spinal networks, early work supported the half-center model (Grillner, 1981, 2006; Orlovsky et al., 1999), but the second model has found some support in recent studies (Berg et al., 2007).

Our work in Aplysia suggests that both alternating and concurrent excitation and inhibition is present in the feeding network, but the two forms of control may be used for different output neurons. For protraction motoneurons (e.g., B31/32) (Fig. 12 B1) that have stable phase relationships in all program types, the control may be primarily accomplished by alternating excitation and inhibition. For example, $\mathrm{B} 31 / 32$ receives primarily excitation during the agonist phase (protraction) and primarily inhibition during the antagonist phase (retraction), resulting in phasic activity only during protraction. Consistent with this, during retraction, B31/32 appears to be hyperpolarized by the retraction interneurons (Hurwitz and Susswein, 1996; Sasaki et al., 2007). Moreover, the intrinsic properties of B31/32, such as its ability to generate plateau potentials, are critical for shaping the entire burst of protraction activity (Hurwitz et al., 1994; Dembrow et al., 2004). Alternating excitation and inhibition may provide effective control of neurons performing tasks of this kind.

Here, in contrast, we showed that the variable activity of the radula closing motoneuron B8 (Fig. 12 B2) appears to be controlled by concurrent excitation and inhibition during a single program phase, retraction. The same is probably also true during protraction because B8 is postsynaptic to excitatory and inhibitory interneurons that are active during protraction (Hurwitz et al., 1997; Jing and Weiss, 2001, 2002). Similar to other neurons receiving concurrent excitation and inhibition (Softky and Koch, 1993; Destexhe et al., 2003; Alaburda et al., 2005; Berg et al., 2007), B8 exhibits a high-conductance state during both protraction and retraction and fires in a more irregular manner during retraction than does B31/32 during protraction. The concurrent control scheme for $\mathrm{B} 8$ may be effective in producing, during retraction, the high $\mathrm{B} 8$ activity in ingestive programs but low activity in egestive programs. The excitation of B8 may predispose B8 to spike in both phases, but the amount of superimposed inhibition will then govern the final activity so as to produce the different motor program types. It has been shown computationally that, in cortical neurons receiving concurrent excitation and inhibition, the inhibitory conductance predominates and that lowering the level of inhibition may be used to enable differential firing during various states (Rudolph et al., 2007). Because in Aplysia, depending on its network state, the feeding CPG generates different types of programs, one main function of the concur- rent excitation and inhibition may thus be to control the activity of motoneurons in a state-dependent manner.

Moreover, by using multiple inhibitory neurons with temporally specific activity, concurrent excitation and inhibition allows an additional level of flexibility in the generation of motor outputs. Two types of CPG neurons, B4/5 and B70, exert the inhibitory control on $\mathrm{B} 8$ to promote egestive programs. Coregulation of both B4/5 and B70 by the ingestion-promoting descending interneuron CBI-3 allows state-dependent control. At other times, however, particularly if B4/5 and B70 are only moderately active (Fig. $5 B$ ), when programs are likely to be intermediate, the activities of B4/5 and B70 may differ. A low B70 activity and high B4/5 activity will result in higher B8 activity during the late part of retraction, and high B70 activity and low B4/5 activity will result in higher $\mathrm{B} 8$ activity during the early part of retraction (Fig. $5 C$ ). Consistent with this, previous work has suggested that intermediate programs may be divided into at least two types (Wu et al., 2007), and this may be true even of egestive programs (Ye et al., 2006). Additionally, although sharing many features, $B 4 / 5$ and B70 do differ in some morphological and functional features. First, B4/5 has peripheral functions: it sends its axon to the periphery and may function as a motoneuron (Evans et al., 1996) or a sensory neuron (Fiore and Geppetti, 1981; Jahan-Parwar et al., 1983). In contrast, B70 is purely an interneuron; its axon does not exit the buccal ganglion. Second, B4/5 projects only ipsilaterally and therefore inhibits only the ipsilateral B8, whereas B70 also projects contralaterally to inhibit both B8s. Like many other CPG interneurons with bilateral projections, $\mathrm{B} 70$ may thus coordinate the activity of bilateral neurons, whereas B4/5 interacts with peripheral targets. It may thus be that, in more intact preparations in which B4/5 integrates information from the periphery, B4/5 and B70 may show additional differential activity. Regardless of the specific circumstances, however, the use of dual inhibitors will 
A

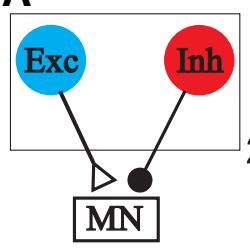

1. Reciprocal model

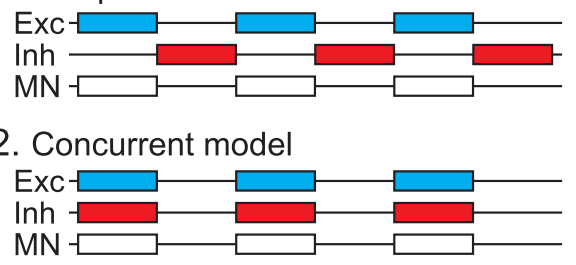

B 1
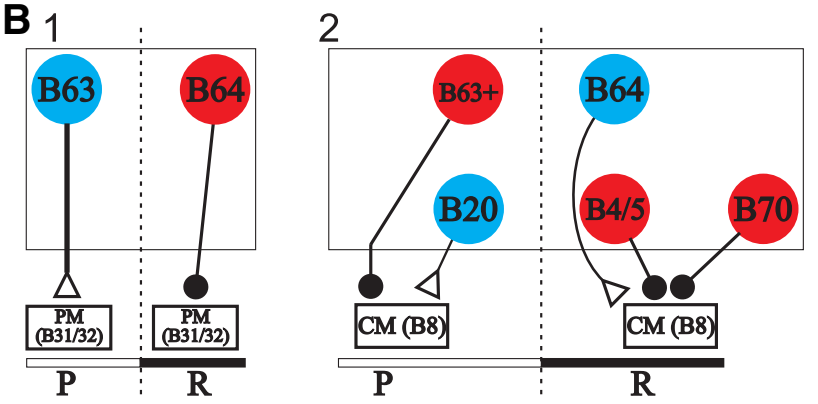

Figure 12. Neural control models with alternate (reciprocal) or concurrent excitation and inhibition. $\boldsymbol{A}$, The two models of rhythmic motoneuronal activity (Berg et al., 2007). In $\boldsymbol{A}$, excitation (Exc, blue) and inhibition (Inh, red) are reciprocal or alternated so that the motoneuron (MN) is active in-phase with the excitatory inputs, whereas the inhibition is responsible for terminating the activity of the motoneuron. In $\mathbf{A 2}$, excitation and inhibition are concurrent, and the activity of the motoneuron is determined by the relative levels of excitation and inhibition. Thus, one major difference between the models is that the inhibition determines only the phasing of the motoneuronal activity in $\boldsymbol{A} \boldsymbol{1}$ but determines also the level of the activity in $\mathbf{A}$. $\boldsymbol{B}$, Both the reciprocal and concurrent mechanisms may be present in the Aplysia feeding network. In the reciprocal model of $\boldsymbol{B} 1$, radula protraction motoneurons (PM) B31/32 are excited by protraction $(P)$ interneuron $B 63$ and inhibited by retraction $(R)$ interneuron $B 64$, resulting in phasic activity of $B 31 / 32$ only during protraction. In the concurrent model of $\boldsymbol{B} 2$, the radula closing motoneuron (CM) B8 is controlled by concurrent excitation and inhibition during both protraction (left) and retraction (right). During protraction, B8 activity is determined by excitation from B20 and inhibition from B63 and other interneurons (+; e.g., B34 and B40). During retraction, $B 8$ activity is determined by excitation from $B 64$ and inhibition from $B 4 / 5$ and $B 70$. Also shown is the complexity in the inhibitory control by B4/5 and B70: although B4/5 and B70 are both active during retraction, they act preferentially in the early and late part of retraction, respectively, allowing more flexibility in the expression of B8 activity during retraction. Open triangles, Excitation; filled circles, inhibition.

allow the generation of variable motoneuron bursts that differ in their duration or timing within a single motor program phase.

One way of generating distinct motor programs in which some components maintain stable phase relationships and activities whereas other components differ is to use a half-center oscillator for the fixed components and to combine it with concurrent excitation and inhibition for the variable components (Fig. 12 B). In spinal networks (Orlovsky et al., 1999; Frigon and Rossignol, 2006; McCrea and Rybak, 2007), a biphasic halfcenter model may account for the alternating activity of flexors and extensors. However, variable motor neurons pools, such as those for bifunctional muscles that flex one joint and extend another, suggest that a triphasic model may be needed. Finally, a synthetic model integrating elements of biphasic and triphasic models has been proposed (Gelfand et al., 1988; Ivashko et al., 2003). The Aplysia model is similar to the synthetic model in that it combines a half-center oscillator with additional controllers to explain the generation of distinct motor outputs. However, our work underscores the importance of inhibitory neurons, whereas the synthetic model postulated additional excitatory neurons. Because at least some elements of spinal networks are controlled by concurrent excitation and inhibition (Berg et al., 2007), it is conceivable that network mechanisms like those in Aplysia may also operate in spinal networks.
In summary, concurrent excitation and inhibition may be an effective means of controlling the activity of output neurons in a state-dependent manner. More generally, temporally specific control of motoneuronal activity by two inhibitory inputs is effectively a form of spike timing control. Commonly studied spike timing control mechanisms include precise timing of individual spikes (Bi and Poo, 1998) and timing of the initiation or termination of a burst (Rossignol et al., 2006; Wu et al., 2007; Sasaki et al., 2008). Our work thus adds another mechanism. Because state dependence and timing control are pervasive phenomena not only in the simple networks of Aplysia and other invertebrates (Nusbaum and Beenhakker, 2002; Marder et al., 2005) but also in vertebrate networks (Orlovsky et al., 1999; Grillner, 2006), including cortical networks (Destexhe and Contreras, 2006; Robbe et al., 2006), the mechanisms demonstrated here may have broad relevance.

\section{References}

Alaburda A, Russo R, MacAulay N, Hounsgaard J (2005) Periodic highconductance states in spinal neurons during scratch-like network activity in adult turtles. J Neurosci 25:6316-6321.

Baca SM, Marin-Burgin A, Wagenaar DA, Kristan WB Jr (2008) Widespread inhibition proportional to excitation controls the gain of a leech behavioral circuit. Neuron 57:276-289.

Berg RW, Alaburda A, Hounsgaard J (2007) Balanced inhibition and excitation drive spike activity in spinal half-centers. Science 315:390-393.

Berg RW, Ditlevsen S, Hounsgaard J (2008) Intense synaptic activity enhances temporal resolution in spinal motoneurons. PLoS One 3:e3218.

Berkowitz A, Stein PS (1994) Activity of descending propriospinal axons in the turtle hindlimb enlargement during two forms of fictive scratching: broad tuning to regions of the body surface. J Neurosci 14:5089-5104.

Bi GQ, Poo MM (1998) Synaptic modifications in cultured hippocampal neurons: dependence on spike timing, synaptic strength, and postsynaptic cell type. J Neurosci 18:10464-10472.

Brown TG (1911) The intrinsic factors in the act of progression in the mammal. Proc R Soc Lond B Biol Sci 84:308-319.

Chiel HJ, Weiss KR, Kupfermann I (1986) An identified histaminergic neuron modulates feeding motor circuitry in Aplysia. J Neurosci 6:2427-2450.

Church PJ, Lloyd PE (1994) Activity of multiple identified motor neurons recorded intracellularly during evoked feedinglike motor programs in Aplysia. J Neurophysiol 72:1794-1809.

Combes D, Meyrand P, Simmers J (1999) Motor pattern specification by dual descending pathways to a lobster rhythm-generating network. J Neurosci 19:3610-3619.

Dembrow NC, Jing J, Brezina V, Weiss KR (2004) A specific synaptic pathway activates a conditional plateau potential underlying protraction phase in the Aplysia feeding central pattern generator. J Neurosci 24:5230-5238.

Destexhe A, Contreras D (2006) Neuronal computations with stochastic network states. Science 314:85-90.

Destexhe A, Rudolph M, Paré D (2003) The high-conductance state of neocortical neurons in vivo. Nat Rev Neurosci 4:739-751.

Due MR, Jing J, Weiss KR (2004) Dopaminergic contributions to modulatory functions of a dual-transmitter interneuron in Aplysia. Neurosci Lett 358:53-57.

Evans CG, Cropper EC (1998) Proprioceptive input to feeding motor programs in Aplysia. J Neurosci 18:8016-8031.

Evans CG, Rosen S, Kupfermann I, Weiss KR, Cropper EC (1996) Characterization of a radula opener neuromuscular system in Aplysia. J Neurophysiol 76:1267-1281.

Evans CG, Jing J, Rosen SC, Cropper EC (2003a) Regulation of spike initiation and propagation in an Aplysia sensory neuron: gating-in via central depolarization. J Neurosci 23:2920-2931.

Evans CG, Jing J, Proekt A, Rosen SC, Cropper EC (2003b) Frequencydependent regulation of afferent transmission in the feeding circuitry of Aplysia. J Neurophysiol 90:3967-3977.

Fiore L, Geppetti L (1981) Neural control of buccal mass activity in Aplysia. In: Neurobiology of invertebrates (Salánki J, ed), pp 201-223. Oxford: Pergamon.

Frigon A, Rossignol S (2006) Experiments and models of sensorimotor interactions during locomotion. Biol Cybern 95:607-627. 
Gardner D (1971) Bilateral symmetry and interneuronal organization in the buccal ganglia of Aplysia. Science 173:550-553.

Gelfand IM, Orlovsky GN, Shik ML (1988) Locomotion and scratching in tetrapods. In: Neural control of rhythmic movements in vertebrates (Cohen AH, Rossignol S, Grillner S, eds), pp 167-199. New York: Wiley.

Grillner S (1981) Control of locomotion in bipeds, tetrapods, and fish. In: Handbook of physiology, Sec 1, Vol 2 (Brooks V, ed), pp 1179-1236. Bethesda, MD: American Physiological Society.

Grillner S (2006) Biological pattern generation: the cellular and computational logic of networks in motion. Neuron 52:751-766.

Holt GR, Softky WR, Koch C, Douglas RJ (1996) Comparison of discharge variability in vitro and in vivo in cat visual cortex neurons. J Neurophysiol 75:1806-1814.

Hurwitz I, Susswein AJ (1996) B64, a newly identified central pattern generator element producing a phase switch from protraction to retraction in buccal motor programs of Aplysia californica. J Neurophysiol 75:1327-1344.

Hurwitz I, Goldstein RS, Susswein AJ (1994) Compartmentalization of pattern-initiation and motor functions in the B31 and B32 neurons of the buccal ganglia of Aplysia californica. J Neurophysiol 71:1514-1527.

Hurwitz I, Neustadter D, Morton DW, Chiel HJ, Susswein AJ (1996) Activity patterns of the $\mathrm{B} 31 / \mathrm{B} 32$ pattern initiators innervating the $\mathrm{I} 2$ muscle of the buccal mass during normal feeding movements in Aplysia californica. J Neurophysiol 75:1309-1326.

Hurwitz I, Kupfermann I, Susswein AJ (1997) Different roles of neurons B63 and B34 that are active during the protraction phase of buccal motor programs in Aplysia californica. J Neurophysiol 78:1305-1319.

Ivashko DG, Prilutsky BI, Markin SN, Chapin JK, Rybak IA (2003) Modeling the spinal cord neural circuitry controlling cat hindlimb movement during locomotion. Neurocomputing 52:621-629.

Jahan-Parwar B, Wilson AH Jr, Fredman SM (1983) Role of proprioceptive reflexes in control of feeding muscles of Aplysia. J Neurophysiol 49:1469-1480.

Jing J, Weiss KR (2001) Neural mechanisms of motor program switching in Aplysia. J Neurosci 21:7349-7362.

Jing J, Weiss KR (2002) Interneuronal basis of the generation of related but distinct motor programs in Aplysia: implications for current neuronal models of vertebrate intralimb coordination. J Neurosci 22:6228-6238.

Jing J, Weiss KR (2005) Generation of variants of a motor act in a modular and hierarchical motor network. Curr Biol 15:1712-1721.

Jing J, Vilim FS, Wu JS, Park JH, Weiss KR (2003) Concerted GABAergic actions of Aplysia feeding interneurons in motor program specification. J Neurosci 23:5283-5294.

Jing J, Cropper EC, Hurwitz I, Weiss KR (2004) The construction of movement with behavior-specific and behavior-independent modules. J Neurosci 24:6315-6325.

Jing J, Vilim FS, Horn CC, Alexeeva V, Hatcher NG, Sasaki K, Yashina I, Zhurov Y, Kupfermann I, Sweedler JV, Weiss KR (2007) From hunger to satiety: reconfiguration of a feeding network by Aplysia neuropeptide Y. J Neurosci 27:3490-3502.

Kabotyanski EA, Baxter DA, Byrne JH (1998) Identification and characterization of catecholaminergic neuron $B 65$, which initiates and modifies patterned activity in the buccal ganglia of Aplysia. J Neurophysiol 79:605-621.

Marder E, Bucher D, Schulz DJ, Taylor AL (2005) Invertebrate central pattern generation moves along. Curr Biol 15:R685-R699.

McCrea DA, Rybak IA (2007) Modeling the mammalian locomotor CPG: insights from mistakes and perturbations. Prog Brain Res 165:235-253.

Morgan PT, Jing J, Vilim FS, Weiss KR (2002) Interneuronal and peptidergic control of motor pattern switching in Aplysia. J Neurophysiol 87:49-61.

Mortin LI, Keifer J, Stein PS (1985) Three forms of the scratch reflex in the spinal turtle: movement analyses. J Neurophysiol 53:1501-1516.

Morton DW, Chiel HJ (1993a) In vivo buccal nerve activity that distinguishes ingestion from rejection can be used to predict behavioral transitions in Aplysia. J Comp Physiol 172:17-32.

Morton DW, Chiel HJ (1993b) The timing of activity in motor neurons that produce radula movements distinguishes ingestion from rejection in Aplysia. J Comp Physiol 173:519-536.

Nargeot R, Baxter DA, Byrne JH (1997) Contingent-dependent enhancement of rhythmic motor patterns: an in vitro analog of operant conditioning. J Neurosci 17:8093-8105.

Nusbaum MP, Beenhakker MP (2002) A small-systems approach to motor pattern generation. Nature 417:343-350.

Orlovsky GN, Deliagina TG, Grillner S (1999) Neural control of locomotion. New York: Oxford UP.

Plummer MR, Kirk MD (1990) Premotor neurons B51 and B52 in the buccal ganglia of Aplysia californica: synaptic connections, effects on ongoing motor rhythms, and peptide modulation. J Neurophysiol 63:539-558.

Proekt A, Brezina V, Weiss KR (2004) Dynamical basis of intentions and expectations in a simple neuronal network. Proc Natl Acad Sci U S A 101:9447-9452.

Proekt A, Jing J, Weiss KR (2007) Multiple contributions of an inputrepresenting neuron to the dynamics of the Aplysia feeding network. J Neurophysiol 97:3046-3056.

Proekt A, Wong J, Zhurov Y, Kozlova N, Weiss KR, Brezina V (2008) Predicting adaptive behavior in the environment from central nervous system dynamics. PLoS One 3:e3678.

Robbe D, Montgomery SM, Thome A, Rueda-Orozco PE, McNaughton BL, Buzsaki G (2006) Cannabinoids reveal importance of spike timing coordination in hippocampal function. Nat Neurosci 9:1526-1533.

Rosen SC, Teyke T, Miller MW, Weiss KR, Kupfermann I (1991) Identification and characterization of cerebral-to-buccal interneurons implicated in the control of motor programs associated with feeding in Aplysia. J Neurosci 11:3630-3655.

Rosen SC, Miller MW, Evans CG, Cropper EC, Kupfermann I (2000) Diverse synaptic connections between peptidergic radula mechanoafferent neurons and neurons in the feeding system of Aplysia. J Neurophysiol $83: 1605-1620$.

Rossignol S (1996) Neural control of stereotypic limb movements. In: Handbook of physiology (Rowell LB, Sheperd JT, eds), pp 173-216. New York: Oxford UP.

Rossignol S, Dubuc R, Gossard JP (2006) Dynamic sensorimotor interactions in locomotion. Physiol Rev 86:89-154.

Rudolph M, Pospischil M, Timofeev I, Destexhe A (2007) Inhibition determines membrane potential dynamics and controls action potential generation in awake and sleeping cat cortex. J Neurosci 27:5280-5290.

Sasaki K, Due MR, Jing J, Weiss KR (2007) Feeding CPG in Aplysia directly controls two distinct outputs of a compartmentalized interneuron that functions as a CPG element. J Neurophysiol 98:3796-3801.

Sasaki K, Jing J, Due MR, Weiss KR (2008) An input-representing interneuron regulates spike timing and thereby phase switching in a motor network. J Neurosci 28:1916-1928.

Smith JL, Carlson-Kuhta P, Trank TV (1998) Motor patterns for different forms of walking: cues for the locomotor central pattern generator. Ann N Y Acad Sci 860:452-455.

Softky WR, Koch C (1993) The highly irregular firing of cortical cells is inconsistent with temporal integration of random EPSPs. J Neurosci 13:334-350.

Stein PS, Smith JL (1997) Neural and biomechanical control strategies for different forms of vertebrate hindlimb motor tasks. In: Neurons, networks, and motor behavior (Stein PSG, Grillner S, Selverston AI, Stuart DG, eds), pp 61-73. Cambridge, MA: MIT.

van Vreeswijk C, Sompolinsky H (1996) Chaos in neuronal networks with balanced excitatory and inhibitory activity. Science 274:1724-1726.

Wu JS, Due MR, Sasaki K, Proekt A, Jing J, Weiss KR (2007) State dependence of spike timing and neuronal function in a motor pattern generating network. J Neurosci 27:10818-10831.

Ye H, Morton DW, Chiel HJ (2006) Neuromechanics of multifunctionality during rejection in Aplysia californica. J Neurosci 26:10743-10755. 